\title{
WestVirginiaUniversity
}

THE RESEARCH REPOSITORY @ WVU

Graduate Theses, Dissertations, and Problem Reports

2014

\section{Age and Gender Differences in Decision-Making Style Profiles}

Rebecca K. Delaney

Follow this and additional works at: https://researchrepository.wvu.edu/etd

\section{Recommended Citation}

Delaney, Rebecca K., "Age and Gender Differences in Decision-Making Style Profiles" (2014). Graduate Theses, Dissertations, and Problem Reports. 5465.

https://researchrepository.wvu.edu/etd/5465

This Thesis is protected by copyright and/or related rights. It has been brought to you by the The Research Repository @ WVU with permission from the rights-holder(s). You are free to use this Thesis in any way that is permitted by the copyright and related rights legislation that applies to your use. For other uses you must obtain permission from the rights-holder(s) directly, unless additional rights are indicated by a Creative Commons license in the record and/ or on the work itself. This Thesis has been accepted for inclusion in WVU Graduate Theses, Dissertations, and Problem Reports collection by an authorized administrator of The Research Repository @ WVU. For more information, please contact researchrepository@mail.wvu.edu. 
Age and Gender Differences in Decision-Making Style Profiles

Rebecca K. Delaney, B.A.

Thesis submitted to the Eberly College of Arts and Sciences

at West Virginia University

in partial fulfillment of the requirements

for the degree of

Master of Science

in

Psychology

JoNell Strough, Ph.D. Chair

Barry Edelstein, Ph.D.

Melissa Blank, Ph.D.

Department of Psychology

Morgantown, West Virginia

2014

Keywords: decision making, decision-making styles, gender differences, age differences

Copyright 2014 Rebecca Delaney 


\begin{abstract}
Age and Gender Differences in Decision-Making Style Profiles
\end{abstract}

\title{
Rebecca Delaney
}

The current study examined Scott and Bruce’s (1995) five decision-making styles (i.e. rational, intuitive, spontaneous, dependent, and avoidant) to assess potential combinations of styles using cluster analysis. The sample comprised 1,075 members from RAND's American Life Panel (56.2\% female, 18-93 years, Mage $=53.49)$. Data was collected from a larger survey that members completed on a monthly basis. Findings yielded a three-cluster model which included: affective/experiential, dependent, and independent/self-controlled decision-making style profiles. These profiles were significantly differentiated by age and gender. Older age and being female was associated with being more likely to be in the independent/self-controlled decision-making style profile than the affective/experiential decision-making style profile. The findings provide a new perspective for examining how people approach decisions and provide support for certain aspects of decision-making process theories. 


\section{ACKNOWLEDGEMENTS}

I would like to thank Dr. JoNell Strough, my academic advisor and thesis chair, for her advice and support throughout this project. In addition, I would like to thank the RAND Corporation for allowing me to utilize data for this project. I also appreciate the time and useful comments that my committee members, Dr. Barry Edelstein and Dr. Melissa Blank, provided. Lastly, my family members and friends have been a huge source of support that I am greatly appreciative for having throughout this process. 
AGE AND GENDER DIFFERENCES IN DECISION MAKING PROFILES

TABLE OF CONTENTS

Page

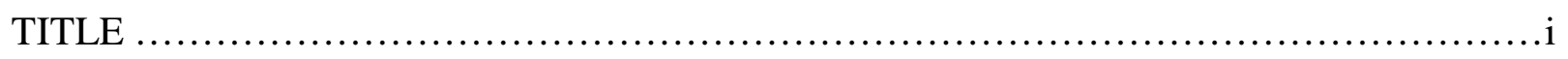

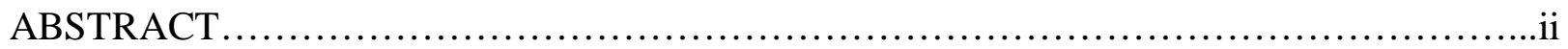

ACKNOWLEDGEMENTS .......................................................ii

TABLE OF CONTENTS .........................................................

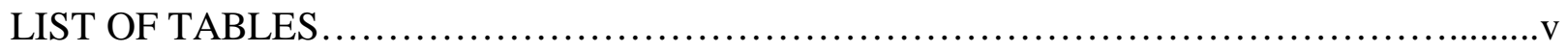

LIST OF FIGURES .............................................................

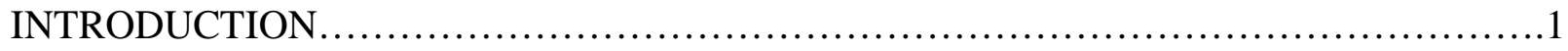

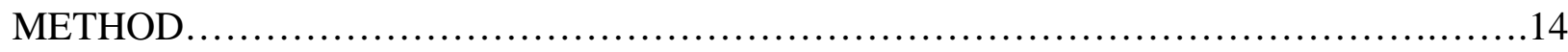

PROCEDURE................................................................... 14

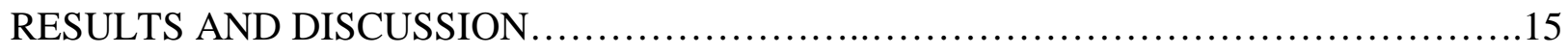

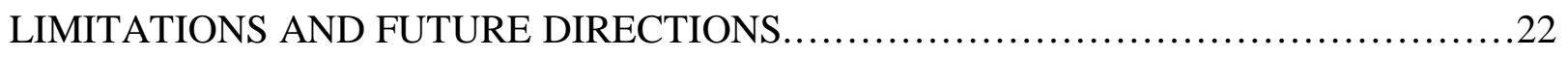

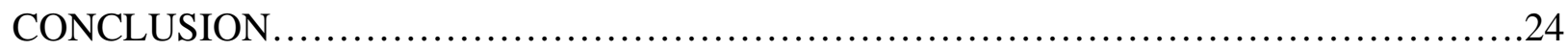

REFERENCES...............................................................25

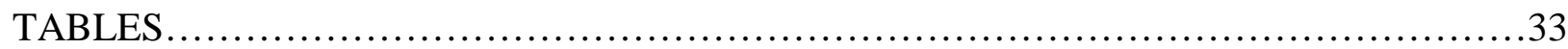

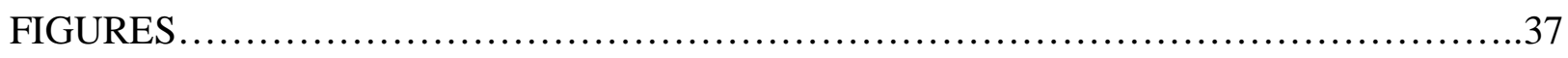

APPENDIX A, GENERAL DECISION-MAKING STYLES INVENTORY ...............40

APPENDIX B, ORIGINALLY PROPOSED ANALYSES .............................41 
AGE AND GENDER DIFFERENCES IN DECISION MAKING PROFILES

\section{LIST OF TABLES}

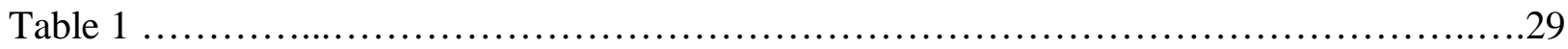

Demographic characteristics

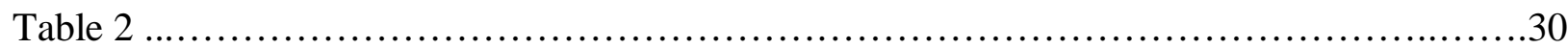

Reliability and descriptive characteristics of the decision-making styles

Table 3 ........................................................................ 31

MANOVA main effects between decision-making style profiles

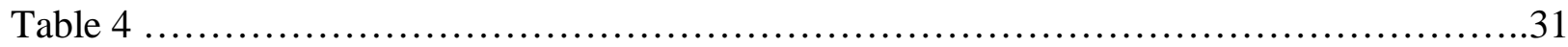

Multinomial logistic regressions 


\section{LIST OF FIGURES}

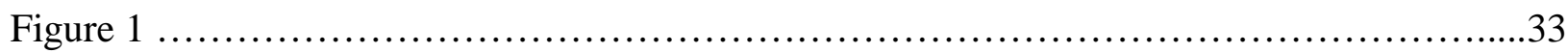

Dendogram depicting three decision-making style clusters

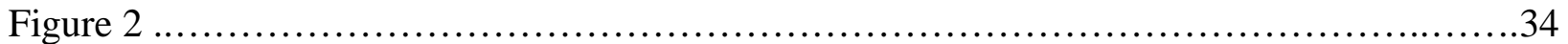

Cluster analysis scree plot

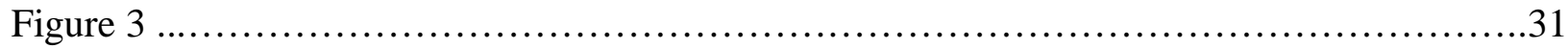

Decision-making styles profile graph 
AGE AND GENDER DIFFERENCES IN DECISION MAKING PROFILES

\section{Introduction}

Everyday people are confronted with situations in which a decision, whether it is minor or major, needs to be made. Recently researchers have begun to consider that there may be individual differences in decision-making styles or response patterns that people report using to make decisions (Scott \& Bruce, 1995). Understanding these styles is important because the manner in which a person approaches decisions has been shown to have important consequences for job performance (Russ, McNeilly, \& Comer, 1996). Both a person’s age and gender may be related to how they approach decisions. Previous research has utilized a variable-centered approach to investigate different decision-making styles separately. For example, men’s and women's reported use of intuition has been compared, and men's and women's reported use of reason has been compared (Sadler-Smith, 2011; Sinclair, Ashkanasay, \& Chattopadhyay, 2010). This type of research yields inconsistent findings about age and gender differences. Examining the decision-making styles from a person-centered approach may provide a better understanding of age and gender differences. Using a person-centered approach, it is possible to determine for example, if people who tend to use reason also tend to be less likely to use intuition (or vice versa) and if individual differences exist in this particular "combination” of styles. In the current study, cluster analytic techniques were used instead of examining each variable separately to identify distinct decision-making style profiles.

\subsection{Dual-process conceptualizations of decision-making}

One way theorists have tried to understand how people make decisions is to propose “dual-process” models that distinguish two different systems or modes of decisions (Epstein, 1994; Evans, 2008; Kahneman, 2003; Osman, 2004; Stanovich \& West, 2000). One system is described as unconscious, immediate reactions that do not require purposeful thought—-that is, 
AGE AND GENDER DIFFERENCES IN DECISION MAKING PROFILES

decisions are based on intuition, experience, and affective responses. The other system is proposed to be analytic, computational, rational, and deliberative. The rational, deliberative system is also thought to be responsible for altering or nullifying biased decisions that come from the intuitive, experiential affective system (Evans, 2008; Kahneman, 2003). In these dualprocess models, “good” (i.e., unbiased decisions) are based on deliberation and analysis. In contrast, Reyna’s (2004) fuzzy trace theory suggests that the more intuitive, experiential system is the source of good decisions. Those who are more experienced have a greater knowledge base that allows them to use gist-based processing (i.e. focus on overall pertinent information) and make faster decisions; whereas those who are inexperienced may have to be more deliberative and slower when making decisions. Others have suggested that the decision making process may be better conceptualized as involving an interplay between three overlapping systems (i.e. deliberative, experiential, and affective) which highlights that decision-making approaches may not always happen separate from one another (Strough, Karns, \& Schlosnagle, 2011). Other criticisms of dual-process models also exist (e.g., Keren \& Schul, 2009) with recent attention being directed toward whether evidence supports two distinct systems (Evans \& Stanovich, 2013; Frank, Cohen, \& Sanfey, 2009; Keren, 2013; Kruglanski, 2013). Although dual-process models have been criticized for being inadequate, they have served as a guide for much of the contemporary research on decision making and thus provide a useful way of organizing prior research.

\subsection{Decision-making styles}

Ideas consistent with dual-process models are apparent in the decision-making styles proposed by Scott and Bruce (1995). Scott and Bruce’s (1995) General Decision-Making Styles Inventory (GDMS) consists of five subscales. First, the rational decision-making style is 
AGE AND GENDER DIFFERENCES IN DECISION MAKING PROFILES

characterized as evaluating alternatives to decisions in a logical manner (which would correspond to the deliberative system in dual-process models). Second, the intuitive decisionmaking style is characterized as relying on feelings and "hunches" when confronted with a decision (which would correspond to the intuitive, affective experiential system). Third, the spontaneous decision-making style reflects making decisions quickly. The spontaneous style has been found to have a significant, positive association with the intuitive decision-making style suggesting that the spontaneous decision-making style may reflect a fast intuitive response (Baiocco, Laghi, \& D'Alessio, 2009; Loo, 2000; Thunholm, 2004). Fourth, the dependent decision-making style is characterized as seeking out advice and help from others when faced with a decision. Lastly, the avoidant decision-making style is characterized as postponing or avoiding decisions (Scott \& Bruce, 1995). The dependent and avoidant decision-making styles do not directly correspond to dual-process models, but they may differentiate how people approach decisions, and could potentially co-occur with other decision styles, as is discussed in more detail later.

1.2.1 Person-centered approach. Past research utilizing the General Decision-Making Styles Inventory (Scott \& Bruce, 1995) with four samples (i.e. male military officers, engineers/technicians, and both undergraduate and graduate business students) evaluated each style separately using a variable-centered approach. The variable-centered approach is limited, because it cannot depict whether there is a composite of styles that a person uses to approach decisions on a daily basis. Due to the styles not being mutually exclusive, participants can report using multiple styles rather than just one (Loo, 2000; Scott \& Bruce, 1995; Spicer \& SadlerSmith, 2005). For example, in work with adolescents and undergraduate business majors those who were more likely to report using an avoidant decision-making style were also more likely to 
AGE AND GENDER DIFFERENCES IN DECISION MAKING PROFILES

report using a spontaneous decision-making style (Baiocco et al., 2009; Spicer \& Sadler-Smith, 2005). These interrelations among subscales suggest that it may be important to investigate whether there are certain groups of people that rely on a similar combination of styles and what individual differences distinguish these groups; issues which the variable-centered approach is unable to determine.

\subsection{Age differences in decision making}

1.3.1 Rational and intuitive decision-making styles. Dual-process theories of decisionmaking have been extended to suggest that older and younger adults' decision making may differ (e.g., Peters, Hess, Västfjäll, \& Auman, 2007). Hence, research investigating age differences tends to focus on age differences in rationality versus intuition. Peters and colleagues (2007) theorize that as cognitive abilities used for the rational, deliberative system of decision making decline in older age (e.g. Babcock \& Salthouse, 1990; Verhaeghen, Marcoen, \& Goossens, 1993), adults may shift to relying on intuition and affect. Affective processing is relatively wellpreserved with age and may even improve (Charles \& Carstensen, 2010; Kennedy \& Mather, 2007; Mather \& Carstensen, 2005). For example, with increasing age, adults’ working memory abilities decline, but one exception is emotion processing for working memory which remains relatively intact in old age (Mikels, Larken, Reuter-Lorenz, \& Carstensen, 2005). Age-related declines such as cortical thinning and receptor loss in areas of the brain responsible for decisionmaking, such as the pre-frontal cortex, may also underlie cognitive declines (for a review see Marschner et al., 2005; Raz \& Rodrigue, 2006, Salat et al., 2004). With a decline in the effortful and deliberative working memory processes with age, the likelihood of reporting a rational decision-making style may decline with age. If people compensate for age-related cognitive 
AGE AND GENDER DIFFERENCES IN DECISION MAKING PROFILES

declines by relying on quick, gut reactions or feelings, the likelihood of reporting an intuitive decision-making style may increase with age.

Although the idea from dual-process models of aging that older people rely more affective/experiential or "intuitive" processes and less on deliberative is pervasive, yet studies that have used the General Decision-Making Styles Inventory yield discrepant findings regarding associations of the rational and intuitive decision-making styles with age. One study of community-dwelling adults ages18 to 88 years old found that as age increased, adults were more likely to report using both intuitive and rational decision-making styles (Bruine de Bruin, Parker, \& Fischoff, 2007). A study of undergraduates with ages ranging from 19 to 50 years old, found that as age increased, adults were less likely to report using an intuitive decision-making style (Loo, 2000). Results of both of these studies are in opposition to the dual-process theories of aging, which suggests that as adults age, rationality decreases and intuition increases as a way of compensating for cognitive deficits (Peters et al., 2007).

1.3.2 Spontaneous decision-making style. Little research has addressed the relation between age and the other three decision-making styles (i.e. spontaneous, dependent, and avoidant). Because prior research shows that the spontaneous decision-making style is highly correlated with the intuitive decision-making style in samples of adolescents, management undergraduates, and military officers (Baiocco et al., 2009; Loo, 2000; Thunholm, 2004), it could be argued that the association between age and these two decision-making styles would be similar. Thus, in addition to reporting more use of intuition, older adults may also be more likely to report using a spontaneous decision-making style than younger adults.

1.3.3 Dependent decision-making style. The association between age and the dependent decision-making style has not been the focus of previous literature, however, other research 
AGE AND GENDER DIFFERENCES IN DECISION MAKING PROFILES

suggests that age differences may arise in depending on others when making decisions. For example, Finucane and colleagues (2002) found that older adults (65-94 years) were more likely than younger adults (18-64 years) to report a preference for delegating decisions to others. In addition, one study that interviewed older adults (53-84 years old) and asked them to discuss thoughts about future financial, health, and social care decisions found that some older adults reported that they preferred that their spouse or children make future plans. However, other older adults did not want to burden their families and preferred making decisions on their own (Samsi \& Manthorpe, 2011). These findings suggest that some older adults may exhibit a dependent decision-making style, but that there are individual differences among older adults’ preferences for making decisions with others.

The reasoning behind depending on others when making decisions is relatively unclear. For example, a person may solely rely on others as a way to avoid making important decisions on their own. Baiocco and colleagues (2009) found that among Italian adolescents (ages 15 to 19 years), those who were more likely to report using the dependent decision-making style were also more likely to report using the avoidant decision-making style. In regards to older adults, a decline in comprehension and fluid abilities (Perlmutter \& Nyquist, 1990; for a review see Salthouse, 2012), might increase the likelihood that they choose to depend on others if they perceive declines in their own cognitive functioning. Indeed, everyday problem-solving research shows that older adults choose to include others when their self-perceptions of their problemsolving abilities are lower (Strough, Cheng, Swenson, 2002). Hence, some older adults could show dependence on others because they are using others as a way to compensate for declines in their own decision-making abilities. 
AGE AND GENDER DIFFERENCES IN DECISION MAKING PROFILES

Alternatively, it is also possible that people depend on others as a source of information to check about options. For instance, Loo (2000) found that adults who were more likely to report using a rational decision-making style were also more likely to report using a dependent decision-making style. Having a dependent style under these circumstances might reflect using others' advice as input in a more deliberative form of decision making. Thus, using a dependent decision-making style could have different meanings depending on its co-occurrence with other styles. Previous research shows associations among the rational and avoidant decision-making styles with the dependent decision-making style, which suggests the potential for these three styles to cluster together.

1.3.4 Avoidant decision-making style. Some research has found associations between age and the avoidant decision-making style. For instance, in a study of undergraduates with ages ranging from 19 to 50 years old, Loo (2000) found that as age increased adults were less likely to report using an avoidant decision-making style. This suggests that older adults tend to approach decisions rather than postpone or avoid them. However, older adults were found to be more likely to report a desire to delegate decisions to others (Finucane et al., 2002), which may be a method of avoiding decisions through dependence on others. Similarly, Chen, Ma, and Pethel (2011) found that older adults (60-86 years) were more likely than younger adults (18-25 years) to defer their choice when presented with a trade-off decision task (i.e. having to accept some loss regardless of choice). Furthermore, other studies have found that those who reported using a rational decision-making style were less likely to report using an avoidant decision-making style (Baiocco et al., 2009; Loo, 2000; Scott \& Bruce; Spicer \& Sadler-Smith, 2005). These findings further suggest the importance of examining how styles may cluster together to form different groups and assess potential age differences. 
AGE AND GENDER DIFFERENCES IN DECISION MAKING PROFILES

1.3.5 Summary. Prior work suggests that some decision-making styles may be associated with other styles in systematic ways. Taking this idea into consideration may be useful for understanding age differences. Determining whether the dependent decision-making style forms a decision-making style profile with others, for example, can provide more insight into whether older versus younger adults tend to differ in ways of utilizing others in the decision-making process. Overall, evaluating the composition of decision-making style profiles can help to further identify if there are certain patterns of styles used at different ages.

\subsection{Gender differences in decision-making styles}

Gender stereotypes characterize men and women as fundamentally different. For example, in the popular press and even in some of the psychological literature, women are portrayed as “intuitive” and interpersonally oriented whereas men are portrayed as "rational” and independent in relation to others (e.g. Gilligan, 1982; Gray, 1992; Tannen, 1991). Although these stereotypes are widespread, little research investigates whether men rely more on reason and women rely more on intuition when making decisions. In addition, few studies have addressed whether or not women's relatively greater willingness to seek social support compared to men (Tamres, Janicki, \& Helgeson, 2002; Thoits, 1991) leads women to be dependent on other people to make decisions. The current study addresses this gap in the literature by examining potential gender differences in decision-making style profiles utilizing an adult life-span sample.

1.4.1 Rational and intuitive decision-making styles. Research that has used the General Decision-Making Styles Inventory (Scott \& Bruce, 1995) to investigate gender differences in the rational and intuitive decision-making styles has had inconsistent findings. Sadler-Smith (2011) found that female undergraduates were more likely to report using an intuitive decision-making style. In addition, using a task-specific version of the Scott and Bruce (1995) measure, Sinclair 
AGE AND GENDER DIFFERENCES IN DECISION MAKING PROFILES

and colleagues (2010) found that after a mood inducement and decision-making task, female undergraduates were more likely to report using an intuitive decision-making style, whereas male undergraduates were more likely to report using a rational decision-making style. Other studies, however, have not found significant gender differences with the rational and intuitive decision-making styles (Baiocco et al., 2009; Loo, 2000; Spicer \& Sadler-Smith, 2005).

Discrepancies in the literature could be due to sample characteristics and experimental manipulations. For instance, the effect size in Sadler-Smith’s (2011) study was relatively small and only included first year undergraduate students, whereas other studies had a range of class years. Second, Sinclair and colleagues’ (2010) study required participants to go through a mood inducement procedure (positive, negative, or neutral) and then complete a decision-making task. Thus, the mood inducement procedure could have influenced their findings.

1.4.2 Intuition in the work environment. While few studies focus on gender differences in decision-making styles (i.e. habitual patterns used to make decisions; Baiocco et al., 2009; Loo, 2000; Scott \& Bruce, 1995; Spicer \& Sadler-Smith, 2005), a greater number of studies evaluate gender differences in cognitive styles (i.e. ways of organizing and processing information; Allinson \& Hayes, 1996). Given the conceptual overlap between cognitive and decision-making styles, literature on cognitive styles is useful in understanding potential gender differences (Thunholm, 2000).

Gender differences in intuitive cognitive styles have been examined among specific populations such as managers (Burke \& Miller, 2005; Downey, Papageorgiou, \& Stough, 2006; Hayes, Allinson, \& Armstrong, 2004; Jones, 2002). Burke and Miller (2005) interviewed professionals from the National Management Association to assess professionals’ viewpoints of intuitive decision-making in the workplace regarding their opinions as to whether “women’s 
AGE AND GENDER DIFFERENCES IN DECISION MAKING PROFILES

intuition” exists. The majority of professionals (78\%) did not believe that women were more likely than men to use intuition at work. Similarly, Hayes and colleagues (2004) found that female and male managers were equally likely to report that they used an intuitive orientation, as assess by Allinson and Hayes’ (1996) Cognitive Styles Inventory. In contrast, when Jones (2002) used the Caring Morality Inventory, a measure of feelings, intuition, and concern for others, gender differences were found among managers. Female managers were more likely than male managers to report using an overall caring moral perspective (i.e. a composite score of caring, intuition, and concern for others when making decisions). The inconsistency in findings could be due to the multidimensional nature of approaches used for decisions. For example, the Caring Morality Inventory used in Jones (2002) was comprised of other dimensions, such as concern for others, which may tap into reports of using both intuition and dependency when approaching decisions.

Research has also considered if intuition is more apparent inside or outside of a work environment for men and women. Burke and Miller (2005) interviewed professionals who stated that they believed that women in general employ intuition outside the work environment more than inside a work environment. In contrast, based on self-reports, Hayes et al. (2004) found that female non-managers reported having a less intuitive cognitive-style than female managers. Furthermore, opposite of gender stereotypes, male non-managers were more likely to report an intuitive cognitive-style than female non-managers. With conflicting qualitative and quantitative findings, it is unclear whether or not gender differences in intuition exist. Perhaps discrepancies are due to perceiving others' intuition within the interviews versus participants in Hayes et al. (2004) actually reporting his or her own use of intuition. For the purposes of the current study, we utilize self-report in order to gauge how individuals' report their own decision-making styles. 
AGE AND GENDER DIFFERENCES IN DECISION MAKING PROFILES

Overall, there are many shortcomings to previous research that has examined gender differences in rationality and intuition. Convenience sampling has been used where more research tends to involve undergraduates (Loo, 2000; Sadler-Smith, 2011) or managers (Hayes et al., 2004), thus posing a threat to generalizability of the findings. Moreover, age of the participants in the samples also varied greatly. It is difficult to make inferences about gender differences with samples of vastly different age groups because gender could potentially interact with age. As Hyde (2005) suggests, gender differences may change depending on age. Additionally, based on previous findings by Jones (2002) it may be that gender differences are more likely to arise when a measure examines multiple constructs (e.g. intuition and dependency).

\subsection{Dependent decision-making style}

Little research investigates gender differences in the dependent decision-making style. One study that used the Assessment of Career Decision Making (Harren, 1984), which measures the extent to which individuals approach important decisions in a rational, intuitive, or dependent manner, found that women were more likely to report using a dependent decision-making style than men were (Phillips, Pazienza, \& Ferrin, 1984).

While few studies have focused on gender differences in the dependent decision-making style, research on gender and social support (i.e. perception of supports being available; Barrera, 1986) is more prevalent. Research on gender differences in social support helps to provide insight for potential gender differences in the dependent decision-making style because it addresses reports of getting help, advice, and support from others.

Research suggests that there are differences between men's and women’s use of social support (for a review see Shumaker \& Hill, 1991; Taylor, 2011). Women are more likely to 
AGE AND GENDER DIFFERENCES IN DECISION MAKING PROFILES

utilize multiple people within their social networks (e.g. friends, relatives, and children; Belle, 1987; Depner \& Ingersoll-Dayton, 1988; Gurung, Taylor, \& Seeman, 2003) and seek out support from others especially during times of stress (Taylor, Klein, Lewis, Gruenewald, Gurung, \& Updegraff, 2000) and when dealing with health-related problems (e.g. Strough, McFall, \& Schuller, 2010). In general, men are more likely to report having larger yet less intimate social support networks (Belle, 1987) and tend to report relying more on just one person, their spouse, for emotional support (Belle, 1987; Depner \& Ingersoll-Dayton, 1988; Gurung et al., 2003).

Overall, women seem to take advantage of all types of support more so than men (Belle, 1987). For these reasons, women will potentially be more likely to report using a dependent decision-making style because they could be more likely to consult others (e.g. social support networks), when making decisions. This is in line with Jones’ (2002) study that found that female managers were more likely than male managers to report using an overall caring moral perspective, which included measuring a concern for others when making decisions.

As mentioned previously, it is also important to take into consideration whether individuals who utilize others in the decision-making process are doing so in a way that is deliberative or avoidant. By examining decision-making style profiles formed in the current study we can begin to determine if there are gender differences.

\subsubsection{Spontaneous and avoidant decision-making styles}

Studies that used the General Decision-Making Styles Inventory (Scott \& Bruce, 1995) have either not found gender differences or have not actively investigated gender differences in spontaneous and avoidant decision-making styles. As noted earlier, research that has investigated the spontaneous decision-making style has suggested that it is a faster form of the intuitive decision-making style because the two are highly correlated (Baiocco et al., 2009; Loo, 2000; 
AGE AND GENDER DIFFERENCES IN DECISION MAKING PROFILES

Thunholm, 2004). Given these findings, by examining the spontaneous decision-making style we may be able to further understand potential gender differences.

Due to apparent relationships between the avoidant decision-making style with the other four styles, we might expect it to contribute to distinctions with the decision-making style profiles and gender. The spontaneous and avoidant decision-makings styles will be included in the cluster analysis in an exploratory context. These styles may be able to provide more information regarding relationships among the decision-making styles.

\subsection{Current study}

The overall goal of the current study is to test age and gender differences in decisionmaking styles from a person-centered approach. Research Aim 1 was to explore whether decision-making styles form distinct clusters or profiles and if so, to identify distinguishing features of the profiles. For Research Aim 1, we hypothesized that: (Hypothesis 1) the rational and intuitive decision-making styles will distinguish profiles. Research Aim 2 was to determine if there are systematic age and gender differences in profiles. For Research Aim 2, we hypothesized that: (Hypothesis 2) older individuals would be more likely to be in a profile with greater endorsement of the intuitive, spontaneous, dependent, and avoidant decision-making styles and lower endorsement of the rational decision-making style, (Hypothesis 3) women would be more likely than men to be in a profile with higher prevalence of intuitive and dependent styles, and lower prevalence of the rational decision-making style as central features. This study extends previous literature by gaining knowledge regarding what compositions of decision-making styles emerge and whether there are individual differences associated with the different profiles in a cross-sectional life span sample. 
AGE AND GENDER DIFFERENCES IN DECISION MAKING PROFILES

\section{Method}

\subsection{Participants}

Participants used in the present study were 1,075 members (56.2\% female) of RAND's American Life Panel (ALP) who completed a web-based survey between December 23, 2011 and January 18, 2012. For additional demographic information see Table 1. In exchange for participating in web-based surveys, including the one on which the research is based, ALP members receive approximately $\$ 20$ per 30 minutes of time.

The ALP was originally created to test measures for the Health and Retirement Survey conducted by the University of Michigan. To create the ALP, potential participants were recruited by mailing them an invitation to join the panel. Respondents from the 2006 Michigan Monthly Survey had previously been contacted through random-digit dialing. Those who were mailed an invitation were from the 2006 monthly survey of consumer attitudes conducted by the University of Michigan. If individuals were interested in joining the panel but did not have internet or computer access, they were offered a Web TV to avoid potential biases associated with those having internet access. Since its creation, the ALP has recruited more members through snowballing. More information on the ALP is available at: https://mmicdata.rand.org/alp/

\subsection{Procedure}

Each participant agreed to be a part of the American Life Panel and receive regular invitations to complete surveys. For the current study, an invitation was sent to 1,200 out of 3,474 total ALP members, 1,075 who responded, for a response rate of $90 \%$.

Participants completed the surveys on the computer or WebTV. The measures used for 
AGE AND GENDER DIFFERENCES IN DECISION MAKING PROFILES

this study were from a larger survey. Demographic information was collected followed by the General Decision-Making Styles Inventory.

\subsection{Measures}

2.3.1 Demographics. The demographic questions assessed a variety of individual characteristics including age, gender, ethnicity, highest education attained, and current job status.

2.3.2 Decision-Making Styles. Participants completed the General Decision-Making Styles Inventory (GDMS; Scott \& Bruce, 1995) which measured five different decision-making styles (i.e. rational, intuitive, dependent, avoidant, and spontaneous; see Appendix A). The 25item scale had participants rate on a 5-point Likert scale ranging from 1=strongly disagree, to 5=strongly agree, how each statement applied to how they would go about making important decisions. We found acceptable internal consistency for the five subscales that were used in this study where all of the subscales had Cronbach's alphas greater than .81 (see Table 2).

\section{Results and Discussion}

\subsection{Preliminary Analyses}

Before conducting the main analyses, checks for univariate, bivariate, and multivariate issues were completed. At the univariate level, checks for skewness and kurtosis were completed. The rational decision-making style was significantly, negatively skewed and kurtotic so it was reverse scored and transformed logarithmically. The avoidant decision-making style was significantly, positively skewed and was also transformed logarithmically. The log transformations provided the best change in skewness in comparison to square root so these variables were used in all analyses. All other variables did not appear to pose a significant issue regarding skewness and kurtosis, thus they were not transformed. Bivariate plots and Pearson's $r$ correlations were examined for potential issues (see Table 2). Correlations between some were 
AGE AND GENDER DIFFERENCES IN DECISION MAKING PROFILES

small to moderate, while others were not significantly associated. Due to the large sample size impacting the significance levels, some correlations of small magnitudes were significant. Lastly, there do not appear to be any significant problems regarding multivariate outliers or multicollinearity. Please refer to Table 2 to examine descriptive characteristics of the variables.

\subsection{Aim 1: Decision-Making Style Profiles}

3.2.1. Rational and Intuitive Prevalence. To test Hypothesis 1 , that rational and intuitive styles would be a defining feature of different decision profiles, a cluster analysis was conducted. This analysis addressed whether different decision-making styles co-occurred such that they classified as separate profiles. A two-step cluster analysis approach was used to identify distinct profiles of people who reported using certain decision-making styles. Ward’s hierarchical agglomerative approach for cluster analysis was used first. Based on the dendogram (see Figure 1) and the plots of correlation coefficients (see Figure 2) a 3-cluster solution was identified. The dendogram seemed to depict a 3-cluster solution. The coefficients plot indicated an elbow, or change in the number of factors at the coefficient level of approximately 1058 out of 1061, thus offering further support for a 3-cluster solution.

The second step for the cluster analysis included running a $K$-means analysis using the number of clusters from the hierarchical cluster analysis. After ten iterations, the analysis indicated that the number of cases in each cluster was relatively even. A hierarchical cluster analysis was then conducted again using the specific 3-cluster solution. Lastly, a chi-square cross-tabulation between the hierarchical and $K$-means cluster analyses was completed to assess robustness $\left(\chi^{2}(4,1062)=1251.71, p<.001\right.$; Cluster $1=92.9 \%$, Cluster $2=87.8 \%$, Cluster $3=$ 71.5\%). While there were distinct profiles, there still appeared to be some misclassification, 
AGE AND GENDER DIFFERENCES IN DECISION MAKING PROFILES

especially with Cluster 3, in which approximately $29 \%$ of individuals were misclassified. The robustness of these classifications may therefore be limited.

The three clusters were significantly differentiated from each other $(p<.001$; see Figure 3). For Hypothesis 1, the clusters were assessed to see the prevalence of each decision-making style. The group from Cluster 1 included those who reported high spontaneous, moderately high intuitive and low dependent decision-making styles. To label this cluster, items from the subscales of General Decision Making Styles inventory were reviewed (e.g., making decisions that are "quick," “feel right,” and less likely to "use advice of others”) and thus the cluster was labeled the "affective/experiential" profile. This profile characterized approximately $30 \%$ of the sample ( $N=315,29.7 \%)$. Cluster 2 included those who reported high dependent and slightly low spontaneous decision-making styles; after reviewing the items (e.g. "use advice of others," less “snap” decisions) this cluster was labeled the “dependent” profile ( $N=281,26.5 \%)$. Lastly, Cluster 3 included those who reported a low likelihood of using all of the decision-making styles where the dependent and spontaneous decision-making styles were lower than the other styles; after reviewing the items (e.g. less likely to use "advice of others” or “inner feelings,” “postpone,” or make “quick” decisions), this cluster was labeled the “independent/selfcontrolled” profile; $N=288,27.1 \%)$. Hypothesis 1 was partially supported in that the intuitive decision-making style was more likely to be endorsed; however, the rational decision-making style was not highly endorsed in any of the profiles.

Follow-Up Analysis. To assess decision-making style differences that distinguished the three profiles found, a Multivariate Analysis of Variance (MANOVA) was conducted. There was a statistically significant difference in profiles based on decision-making styles, $\mathrm{F}(5,1055)=$ 13,285.54, Wilk's $\Lambda=0.450, \mathrm{p}<.001$. Significant main effects were found, in which the 
AGE AND GENDER DIFFERENCES IN DECISION MAKING PROFILES

spontaneous and dependent decision-making styles accounted for the most variance (see Table

3). The intuitive decision-making style also accounted for a significant amount of variance, which provides additional support for Hypothesis 1, however, the rational decision-making style accounted for one of the smallest amounts of variance.

3.2.2. Discussion of Aim 1. The decision-making style profiles comprised patterns of decision making that are both similar and different to what previous research would suggest. The composition of the first profile is consistent with the idea of an affective, experiential system outlined in dual-process models (Epstein, 1994; Evans, 2008; Osman, 2004). The affective/experiential profile found in the current study describes individuals who use quick, intuitive judgments and feelings without taking into account advice or support from others. Similar to fuzzy trace theory (Reyna, 2004), those who approach decisions in this manner may be ones who have gained experience to the point where they don't feel the need to get assistance from others, thus they tend to make quick decisions based on intuition and gut reactions.

The second profile is comprised of those who are heavily reliant upon others' advice and assistance when making decisions, therefore they are highly dependent when making decisions. Finding a profile that distinguishes individuals who prefer consulting and taking others' advice into account is in line with previous research that found that some individuals prefer to delegate decisions to others (Finucane et al., 2002; Samsi \& Manthrope, 2011). However, the dependent decision-making profile in this study only assesses utilizing others' help when making decisions, not necessarily having others make decisions for them. Under these circumstances, it may be that getting advice from others is actually part of the decision-making process characterized by more deliberative efforts to gather information in order to make the "best" decision. 
AGE AND GENDER DIFFERENCES IN DECISION MAKING PROFILES

Lastly, the third profile is distinguished by individuals who tend to be more independent and approach decisions in a manner that is not driven by quick, affective reactions. Surprisingly, this group contains those who are more in control of the way they approach decisions which is consistent with the deliberative aspect of the rational system of dual-process models (Kahneman, 2003; Stanovich \& West, 2000), however, the rational decision-making style was not significantly endorsed in this profile. After examining the specific items on the rational decisionmaking style scale (e.g. “double-check information,” "logical and systematic,” “consider various options”), this style appears to be more consistent with the computational and systematic process related to the dual-process system characterized as being more rational.

\subsection{Aim 2: Age and Gender Differences in Profiles}

To test Hypotheses 2 and 3, along with potential age by gender interactions, multinomial logistic regressions were conducted.

3.3.1 Hypothesis 2: Age Differences. It was anticipated that older individuals would be more likely to be in a profile with greater endorsement of the intuitive, spontaneous, dependent, and avoidant decision-making styles. With the independent/self-controlled decision-making style profile as the reference group, the model fit was significant $\chi^{2}(6,1062)=20.04, p=.003$, Cox and Snell $=.019$, and a significant age main effect was found, $\chi^{2}(2,1062)=7.33, p=.026$. The individual parameter estimates indicated that for each year increase in age, individuals were approximately $2 \%$ more likely to be in the independent/self-controlled decision-making style profile than the affective/experiential decision-making style profile. This finding does not support the hypothesis that older individuals would be more likely to be in a profile with greater endorsement of the intuitive, spontaneous, dependent, and avoidant decision-making styles. 
AGE AND GENDER DIFFERENCES IN DECISION MAKING PROFILES

3.3.2. Hypothesis 2: Discussion. Drawing from research that shows that there are declines in cognitive abilities (e.g. Babcock \& Salthouse, 1990; Verhaeghen, Marcoen, \& Goossens, 1993) but maintenance and even improvement in affect regulation (Charles \& Carstensen, 2010; Mather \& Carstensen, 2005) dual process models of aging suggest that with increasing age, these changes could be associated with a shift to relying on the affective, experiential system and less reliance on the deliberative system (Peters et al., 2007). However, the findings from the current study do not align with this hypothesis-older age was not more likely to be associated with the affective/experiential profile. Instead, older age was associated with a decision-making profile that was oriented towards more independence (e.g. low on dependent) and self-control (e.g. low on intuitive, spontaneous, avoidant) when making decisions rather than the affective, experiential profile. The independence in decision making could be due to older individuals not wanting to burden others when making decisions (Samsi \& Manthorpe, 2011). However, it could also be due to older adults having greater a knowledge base from previous experiences and advice from others is considered unnecessary (Reyna, 2004; Strough, Karns, Schlosnagle, 2011).

The low avoidant, intuitive, and spontaneous aspects of the independent, self-control decision-making style profile suggests that older age is associated with confronting decisions in a slower manner. Given important decisions related to health care and finance in late adulthood, for example, may require older adults to take the time to make such decisions because it would be more detrimental to postpone. Of note, however, is that the mean age of our sample was around 54 years, thus depicting a relatively young-old sample in comparison to studies that found that older adults tended to delegate or defer decisions, which had mean ages of 70 and 75 
AGE AND GENDER DIFFERENCES IN DECISION MAKING PROFILES

years old in their older adult sample (Chen et al., 2011; Finucane et al., 2002). The age

differences in the samples could thus provide reasoning behind the discrepant findings.

3.3.3. Hypothesis 3: Gender Differences. It was anticipated that women would be more likely than men to be in a profile with higher prevalence of intuitive and dependent styles, and lower prevalence of the rational decision-making style. A significant main effect was also found for gender, $\chi^{2}(2,1062)=9.82, p=.007$ in the multinomial logistic regression with the independent/self-controlled profile as the reference group. Men were approximately 62\% more likely than women to be in the affective/experiential decision-making style profile than in the independent/self-controlled decision-making style profile. This finding is in opposition to the hypothesis that women would be more likely than men to be in a profile with higher prevalence of intuitive and dependent decision-making styles. No significant age or gender differences were found in the dependent and independent/self-controlled groups (see Table 4).

3.3.4. Hypothesis 3: Discussion. Interestingly, gender differences in the decision-making style profiles challenge societal stereotypes and psychological literature that suggest that women are more likely to use intuition and feelings than men (e.g. Gillian, 1982; Gray, 1992; Tannen, 1991). Men were more likely to be in the decision-making style profile that endorsed use of intuitive and affective responses in a quick manner than the profile that endorsed independence and self-control in taking the time to make decisions. This approach to making decisions could have implications for risky behaviors such as drug use and engaging in unprotected sex, which are more prevalent among males (Byrnes, Miller, \& Schafer, 1999).

A second multinomial logistic regression was conducted with the dependent decisionmaking style profile as the reference group to compare with the affective/experiential decisionmaking style profile and no significant age or gender differences were found. Overall, there were 
AGE AND GENDER DIFFERENCES IN DECISION MAKING PROFILES

also no significant associations in group membership between age by gender interactions and decision-making style profiles (see Table 4).

\subsection{Limitations and Future Directions}

While the current study had strengths such as a large, national sample of individuals across ages, there were some notable limitations. First, the sample consisted of predominantly White individuals (89\%), which influences the generalizability of the clusters found. Having a more diverse ethnic sample can better provide an idea of how people approach decisions. Second, the findings had relatively small effect sizes (e.g. older individuals only $2 \%$ more likely to be in independent/self-controlled profile) and given the large sample size, this could have contributed to the significance of the findings. Future research should study the decision-making style profiles in other samples with a larger proportion of older individuals, for example, to assess whether similar profiles emerge especially in regards to the dependent and avoidant styles being central features. Third, there is potential given the self-report answers, that social desirability may have influenced responses. Women, for instance, may have been less likely to report using items that corresponded to the intuitive decision-making style to avoid endorsing the stereotype that women typically rely on feelings. A social desirability scale could help control for and assess whether this may influence participants answers to decision-making style questions. Fourth, the cross-sectional nature of the study limits our ability to assess how decision-making approaches change as adults get older (Miller, 2007). Utilizing a longitudinal sample along with behavioral decision-making tasks can assist with gaining more insight into how decision-making processes may change across ages. Lastly, there are more specific cognitive processes that could be involved in intuition (for a review see Glöckner \& Witteman, 2010), however, the measurement of intuition using Scott and Bruce’s (1995) scale did not 
AGE AND GENDER DIFFERENCES IN DECISION MAKING PROFILES

capture these distinctions, but instead uses a more global assessment of intuition. Examining other aspects of intuition in future studies could be beneficial in understanding this construct.

Although there are limitations, there are important implications from these findings that should be taken into consideration in future research. First, the decision-making style profiles that emerged offer support for certain attributes associated with dual-process models of decision making. The affective, experiential decision-making style profile lends support for Kahneman’s (2011) perspective that there is a system which is "fast” and the independent, self-controlled decision-making style profile offers support that there is another system that is "slow." The affective, experiential decision-making style profile found in this study captures individuals that tend to report relying on instincts, making decisions quickly, and seem to trust their own knowledge to not require other's advice, which evokes a “fast” decision-making process. The independent, self-controlled decision-making style profile, however, contains individuals who tend to report engaging in a “slower,” more deliberative decision-making process as suggested by reporting a lower likelihood of making quick, affective (or instinctual) decisions and prefer to approach decisions without the use of others' support or advice. Which process is considered an effective way of making decisions, however, is a point of contention based on different decisionmaking theories. According to dual-process models, more rational thinking is believed to lead to “good,” unbiased decisions (Evans, 2008; Kahneman, 2003). However, Reyna’s (2004) fuzzy trace theory suggests that greater knowledge and experience can create the opportunity for individuals to make faster decisions. Examining decision-making style profiles in future studies using real-world scenarios (e.g. gambling, driving) may begin to parse out whether certain approaches are more effective in particular circumstances than others. Furthermore, studies should be conducted regarding the different decision-making style approaches men and women 
AGE AND GENDER DIFFERENCES IN DECISION MAKING PROFILES

use, especially regarding risky behaviors. Interventions could potentially be developed to circumvent decision-making approaches that utilize too fast-paced and affectively-oriented processes if these are found to be detrimental.

\subsection{Conclusions}

We explored the decision-making styles from a person-centered approach to assess age and gender differences in the composition of the styles. We found support for three profiles in which two were differentiated by age and gender. Older adults were more likely and men were less likely to be in the independent/self-controlled decision-making style profile than the affective/experiential decision-making style profile. Future research should continue to study these profiles in comparison to other individual difference characteristics that might distinguish profiles and predict real world outcomes. 
AGE AND GENDER DIFFERENCES IN DECISION MAKING PROFILES

\section{References}

Allinson, C. W., \& Hayes, J. (1996). The cognitive style index: a measure of intuition-analysis for organizational research. Journal of Management Studies, 33(1), 119-135. Retrieved from http://www.talentlens.co.uk/media/71874/csi-manual.pdf

Babcock, R. L., \& Salthouse, T. A. (1990). Effects of increased processing demands on age differences in working memory. Psychology and aging, 5(3), 421 -428. doi:10.1037/0882-7974.5.3.421

Baiocco, R., Laghi, F., \& D'Alessio, M. (2009). Decision-making style among adolescents: Relationship with sensation seeking and locus of control. Journal of Adolescence, 32(4), 963-976. doi:10.1016/j.adolescence.2008.08.003

Belle, D. (1987). Gender differences in the social moderators of stress. In R.C Barnett, L. Biener, G.K. Baruch (Eds), Gender and Stress (pp. 257-277). New York: The Free Press.

Bruine de Bruin, W., Parker, A. M., \& Fischhoff, B. (2007). Individual differences in adult decision-making competence. Journal of personality and social psychology, 92(5), 938956. doi:10.1037/0022-3514.92.5.938

Burke, L. \& Miller, K. (2005). Examining gender differences in intuitive decision making in the workplace: An exploratory investigation. Gender and Behavior, 3, 252-268.

Byrnes, J. P., Miller, D. C., \& Schafer, W. D. (1999). Gender differences in risk taking: A metaanalysis. Psychological Bulletin, 125, 367- 383. doi: 10.1037/0033-2909.125.3.367

Charles, S., \& Carstensen, L. (2010). Social and emotional aging. Annual Review of Psychology, 61, 383-409. doi: 10.1146/annurev.psych.093008.100448

Depner, C. E., \& Ingersoll-Dayton, B. (1988). Supportive relationships in later life. Psychology and Aging, 3(4), 348-357. doi: 10.1037/0882-7974.3.4.348 
AGE AND GENDER DIFFERENCES IN DECISION MAKING PROFILES

Downey, L. A., Papageorgiou, V., \& Stough, C. (2006). Examining the relationship between leadership, emotional intelligence and intuition in senior female managers. Leadership \& Organization Development Journal, 27(4), 250-264. doi: 10.1108/01437730610666019

Epstein, S. (1994). Integration of the cognitive and the psychodynamic unconscious. American Psychologist, 49(8), 709-724. doi:10.1037/0003-066X.49.8.709

Evans, J.S.B. (2008). Dual-processing accounts of reasoning, judgment, and social cognition. Annual Review of Psychology, 59, 255-278. doi:

10.1146/annurev.psych.59.103006.093629

Evans, J. S. B., \& Stanovich, K. E. (2013). Dual-process theories of higher cognition advancing the debate. Perspectives on Psychological Science, 8(3), 223-241. doi: $10.1177 / 1745691612460685$

Frank, M. J., Cohen, M. X., \& Sanfey, A. G. (2009). Multiple systems in decision making: A neurocomputational perspective. Current Directions in Psychological Science, 18(2), 7377. doi: 10.1111/j.1467-8721.2009.01612.x

Finucane, M. L., Slovic, P., Hibbard, J. H., Peters, E., Mertz, C. K., \& MacGregor, D. G. (2002). Aging and decision-making competence: An analysis of comprehension and consistency skills in older versus younger adults considering health-plan options. Journal of Behavioral Decision Making, 15(2), 141-164. doi:10.1002/bdm.40

Gilligan, C. (1982). In a different voice: Psychological theory and women's development. Cambridge, MA: Harvard University Press.

Glöckner, A., \& Witteman, C. (2010). Beyond dual-process models: A categorisation of processes underlying intuitive judgement and decision making. Thinking \& Reasoning, 16(1), 1-25. doi:10.1080/13546780903395748 
AGE AND GENDER DIFFERENCES IN DECISION MAKING PROFILES

Gray, J. (1992). Men are from Mars, women are from Venus: A practical guide for improving communication and getting what you want in your relationships. New York, NY: Harper Collins.

Gurung, R. R., Taylor, S. E., \& Seeman, T. E. (2003). Accounting for changes in social support among married older adults: Insights from the MacArthur Studies of Successful Aging. Psychology and Aging, 18(3), 487-496. doi:10.1037/0882-7974.18.3.487

Harren, V. A. (1984). Assessment of career decision making. Los Angeles, CA: Western Psychological Services.

Hayes, J., Allinson, C. W., \& Armstrong, S. J. (2004). Intuition, women managers and gendered stereotypes. Personnel Review, 33(4), 403-417. doi:10.1108/00483480410539489

Hyde, J. (2005). The Gender Similarities Hypothesis. American Psychologist, 60(6), 581-592. doi:10.1037/0003-066X.60.6.581

Jones, N. J. (2002). Sex and racial differences in preference for a caring morality in a corporate environment that promotes diversity and equal opportunity. Psychological Reports, 91(2), 641-649. doi:10.2466/PR0.91.6.641-649

Kahneman, D. (2003). A perspective on judgment and choice: mapping bounded rationality. American psychologist, 58(9), 697-720. doi: 10.1037/0003-066X.58.9.697

Kahneman, D. (2011). Thinking, fast and slow. New York, NY: Macmillan.

Kennedy, Q., \& Mather, M. (2007). Aging, affect and decision making. In K.D. Vohs, R.F Baumeister, \& G. Loewenstein (Eds.), Do Emotions Help or Hurt Decision Making? A Hedgefoxian perspective (pp. 245-265). 
AGE AND GENDER DIFFERENCES IN DECISION MAKING PROFILES

Keren, G. (2013). A tale of two Systems a scientific advance or a theoretical stone soup?

Commentary on Evans \& Stanovich (2013). Perspectives on Psychological Science, 8(3), 257-262. doi: 10.1177/1745691613483474

Keren, G., \& Schul, Y. (2009). Two is not always better than one a critical evaluation of twosystem theories. Perspectives on Psychological Science, 4(6), 533-550. doi: 10.1111/j.1745-6924.2009.01164.x

Kruglanski, A. W. (2013). Only one? The default interventionist perspective as a unimodel— Commentary on Evans \& Stanovich (2013). Perspectives on Psychological Science, 8(3), 242-247. doi: 10.1177/1745691613483477

Loo, R. (2000). A psychometric evaluation of the General Decision-Making Style Inventory. Personality and Individual Differences, 29(5), 895-905. doi:10.1016/S01918869(99)00241-X

Marschner, A., Mell, T., Wartenburger, I., Villringer, A., Reischies, F. M., \& Heekeren, H. R. (2005). Reward-based decision-making and aging. Brain Research Bulletin, 67(5), 382390. doi: 10.1016/j.brainresbull.2005.06.010

Mather, M., \& Carstensen, L. L. (2005). Aging and motivated cognition: The positivity effect in attention and memory. Trends in Cognitive Sciences, 9(10), 496-502. doi:10.1016/j.tics.2005.08.005

Mikels, J. A., Larkin, G. R., Reuter-Lorenz, P. A., \& Carstensen, L. L. (2005). Divergent trajectories in the aging mind: Changes in working memory for affective versus visual information with age. Psychology and Aging, 20(4), 542-553. doi:10.1037/08827974.20 .4 .542 
AGE AND GENDER DIFFERENCES IN DECISION MAKING PROFILES

Miller, S. A. (2007). Design. In Miller, S.A. (Eds. 3), Developmental research method (pp. 3058). Thousand Oaks, California: Sage Publications.

Osman, M. (2004). An evaluation of dual-process theories of reasoning. Psychonomic Bulletin \& Review, 11(6), 988-1010. doi: 10.3758/BF03196730

Perlmutter, M., \& Nyquist, L. (1990). Relationships between self-reported physical and mental health and intelligence performance across adulthood. Journal of Gerontology, 45(4), 145-155. doi: 10.1093/geronj/45.4.P145

Peters, E., Hess, T. M., Västfjäll, D., \& Auman, C. (2007). Adult age differences in dual information processes: Implications for the role of affective and deliberative processes in older adults' decision making. Perspectives on Psychological Science, 2(1), 1-23. doi:10.1111/j.1745-6916.2007.00025.X

Phillips, S. D., Pazienza, N. J., \& Ferrin, H. H. (1984). Decision-making styles and problemsolving appraisal. Journal of Counseling Psychology, 31(4), 497 -502. doi:10.1037/00220167.31.4.497

Raz, N., \& Rodrigue, K. M. (2006). Differential aging of the brain: patterns, cognitive correlates and modifiers. Neuroscience \& Biobehavioral Reviews, 30(6), 730-748. doi: 10.1016/j.neubiorev.2006.07.001

Russ, F. A., McNeilly, K. M., \& Comer, J. M. (1996). Leadership, decision making and performance of sales managers: A multi-level approach. The Journal of Personal Selling and Sales Management, 1-15. Retrieved from http://www.jstor.org/stable/40471636

Salat, D. H., Buckner, R. L., Snyder, A. Z., Greve, D. N., Desikan, R. S., Busa, E., ... \& Fischl, B. (2004). Thinning of the cerebral cortex in aging. Cerebral cortex, 14(7), 721-730. doi: 10.1093/cercor/bhh032 
AGE AND GENDER DIFFERENCES IN DECISION MAKING PROFILES

Sadler-Smith, E. (2011). The intuitive style: Relationships with local/global and verbal/visual styles, gender, and superstitious reasoning. Learning and Individual Differences, 21(3), 263-270. doi:10.1016/j.lindif.2010.11.013

Samsi, K., \& Manthorpe, J. (2011). 'I live for today': a qualitative study investigating older people's attitudes to advance planning. Health and Social Care in the Community, 19(1), 52-59. doi:10.1111/j.1365-2524.2010.00948.x

Salthouse, T. (2012). Consequences of age-related cognitive declines. Annual Review of Psychology, 63, 201-226. doi: 10.1146/annurev-psych-120710-100328

Scott, S. G., \& Bruce, R. A. (1995). Decision-making style: The development and assessment of a new measure. Educational and psychological measurement, 55(5), 818-831. doi: 10.1177/0013164495055005017

Shumaker, S. A., \& Hill, D. (1991). Gender differences in social support and physical health. Health Psychology, 10(2), 102-111. doi:10.1037/0278-6133.10.2.102

Sinclair, M., Ashkanasy, N. M., \& Chattopadhyay, P. (2010). Affective antecedents of intuitive decision making. Journal of Management \& Organization, 16(3), 382-398. doi:10.5172/jmo.16.3.382

Spicer, D. P., \& Sadler-Smith, E. (2005). An examination of the general decision making style questionnaire in two UK samples. Journal of Managerial Psychology, 20(2), 137-149. doi: $10.1108 / 02683940510579777$

Stanovich, K. E., \& West, R. F. (2000). Individual differences in reasoning: Implications for the rationality debate? Behavioral and brain sciences, 23(5), 645-665. Retrieved from http://www.keithstanovich.com/Site/Research_on_Reasoning_files/bbs2000_1.pdf 
AGE AND GENDER DIFFERENCES IN DECISION MAKING PROFILES

Strough, J., Karns, T. E., \& Schlosnagle, L. (2011). Decision-making heuristics and biases across the life span. Annals of the New York Academy of Sciences, 1235(1), 57-74. doi: doi:10.1111/j.1749-6632.2011.06208.x

Strough, J., McFall, J. P., \& Schuller, K. L. (2010). Endorsement of interpersonal strategies for dealing with hypothetical everyday arthritis problems as a function of marital status, gender, and problem severity. The International Journal of Aging and Human Development, 70(1), 39-59. doi: 10.2190/AG.70.1.b

Tamres, L. K., Janicki, D., \& Helgeson, V. S. (2002). Sex differences in coping behavior: A meta-analytic review and an examination of relative coping. Personality and social psychology review, 6(1), 2-30. Retrieved from http://search.ebscohost.com/login. aspx?direct=true\&db=a9h\&AN=6009031\&site=ehostlive

Tannen, D. (1991). You just don't understand: Women and men in conversation. New York: Ballantine Books.

Taylor, S. E. (2011). Social support: A review. The handbook of health psychology, 189-214. New York: Oxford University Press.

Taylor, S. E., Klein, L. C., Lewis, B. P., Gruenewald, T. L., Gurung, R. A., \& Updegraff, J. A. (2000). Biobehavioral responses to stress in females: tend-and-befriend, not fight-orflight. Psychological review, 107(3), 411-429. doi:10.1037/0033-295X.107.3.411

Thunholm, P. (2004). Decision-making style: habit, style or both? Personality and individual differences, 36(4), 931-944. doi: 10.1016/S0191-8869(03)00162-4 
AGE AND GENDER DIFFERENCES IN DECISION MAKING PROFILES

Reyna, V. F. (2004). How people make decisions that involve risk: A dual-process approach. Current Directions in Psychological Science, 13(2), 60-66. doi: 10.1111/j.09637214.2004.00275.x.

Verhaeghen, P., Marcoen, A., \& Goossens, L. (1993). Facts and fiction about memory aging: A quantitative integration of research findings. Journal of Gerontology, 48(4), 157-171. doi:10.1093/geronj/48.4.P157 
AGE AND GENDER DIFFERENCES IN DECISION MAKING PROFILES

Table 1

Demographic Characteristics

\begin{tabular}{|c|c|c|c|}
\hline Variable & Category & Percent & Means \\
\hline \multirow[t]{4}{*}{ Age } & $18-39$ & 17.9 & \\
\hline & $40-59$ & 47.0 & Mean age $=53.49$ years \\
\hline & $60-69$ & 23.4 & $(S D=14.85 ;$ range $18-93)$ \\
\hline & $70+$ & 11.7 & \\
\hline \multirow[t]{2}{*}{ Gender } & Males & 43.8 & \\
\hline & Females & 56.2 & \\
\hline \multirow[t]{5}{*}{ Ethnicity } & American Indian or Alaskan & 0.7 & \\
\hline & Asian or Pacific Islander & 2.2 & \\
\hline & Black/African American & 7.9 & \\
\hline & White/Caucasian & 84.9 & \\
\hline & Other & 4.3 & \\
\hline \multirow[t]{7}{*}{ Education } & High school graduate or less & 16.8 & \\
\hline & Some college & 23.3 & \\
\hline & Associate's degree & 12.6 & \\
\hline & Bachelor's degree & 27.2 & \\
\hline & Master’s degree & 15.2 & \\
\hline & Professional school & 2.5 & \\
\hline & Doctorate degree & 2.3 & \\
\hline Employment & Currently employed & 59.8 & \\
\hline
\end{tabular}


AGE AND GENDER DIFFERENCES IN DECISION MAKING PROFILES

Table 2

Reliability and Descriptive Characteristics of the Decision-Making Styles

\begin{tabular}{|c|c|c|c|c|c|c|c|c|}
\hline Decision-making styles & $\mathrm{N}$ & $M$ & SD & $\begin{array}{r}\text { Cronbach's } \\
\text { alpha }\end{array}$ & & Correl & tions & \\
\hline & & & & & 1 & 2 & 3 & 4 \\
\hline 1. Rational & 1065 & 4.17 & 0.68 & 0.84 & & & & \\
\hline 2. Intuitive & 1066 & 3.65 & 0.76 & 0.81 & $.16^{* *}$ & & & \\
\hline 3. Dependent & 1066 & 3.11 & 0.91 & 0.85 & $.07 *$ & .01 & & \\
\hline 4. Avoidant & 1066 & 2.12 & 0.87 & 0.86 & $-.28 * *$ & -.02 & $.26^{* *}$ & \\
\hline 5. Spontaneous & 1063 & 2.44 & 0.86 & 0.87 & $-.29 * *$ & $.28 * *$ & -.02 & $.31 * *$ \\
\hline
\end{tabular}


AGE AND GENDER DIFFERENCES IN DECISION MAKING PROFILES

Table 3

MANOVA Main Effects with Decision-Making Styles and Profiles

\begin{tabular}{|c|c|c|c|}
\hline Decision-Making Styles & $\mathrm{df}$ & $\mathrm{F}$ & $\begin{array}{l}\text { partial } \\
\eta 2 \\
\end{array}$ \\
\hline Rational & 2 & 28.95 & 0.54 \\
\hline Intuitive & 2 & 67.69 & 0.46 \\
\hline Dependent & 2 & 461.78 & 0.11 \\
\hline Avoidant & 2 & 26.83 & 0.05 \\
\hline Spontaneous & 2 & 629.55 & 0.05 \\
\hline
\end{tabular}

Note. All main effects were $p<.001$. 
Table 4

Multinomial Logistic Regressions

\begin{tabular}{|c|c|c|c|c|c|}
\hline Variables & & $B(\mathrm{SE})$ & $p$ & $\begin{array}{l}\text { Odds } \\
\text { Ratio }\end{array}$ & $95 \%$ CI \\
\hline \multicolumn{6}{|c|}{$\begin{array}{l}\text { Affective/Experiential vs. } \\
\text { Independent/Self-Controlled }\end{array}$} \\
\hline & Intercept & $1.29(.49)$ & .01 & & \\
\hline & Age & $.02(.01)$ & .01 & 1.022 & $1.005-1.041$ \\
\hline & Gender (Males) & $.48(.16)$ & .00 & 1.616 & $1.193-2.190$ \\
\hline & Age X Gender & $.01(.01)$ & .30 & 1.012 & $.990-1.034$ \\
\hline \multicolumn{6}{|c|}{$\begin{array}{l}\text { Dependent vs. } \\
\text { Independent/Self-Controlled }\end{array}$} \\
\hline & Intercept & $.26(.52)$ & .63 & & \\
\hline & Age & $-.01(.01)$ & .49 & .993 & $.975-1.012$ \\
\hline & Gender (Males) & $.32(.17)$ & .05 & 1.379 & $.997-1.906$ \\
\hline & Age X Gender & $.01(.01)$ & .35 & 1.011 & $.988-1.035$ \\
\hline \multicolumn{6}{|c|}{$\begin{array}{l}\text { Dependent vs. } \\
\text { Affective/Experiential }\end{array}$} \\
\hline & Intercept & $-1.04(.45)$ & .02 & & \\
\hline & Age & $.02(.01)$ & .06 & 1.016 & $.999-1.032$ \\
\hline & Gender (Males) & $-.16(.15)$ & .29 & .853 & $.636-1.145$ \\
\hline & Age X Gender & $.00(.01)$ & .97 & 1 & $.979-1.012$ \\
\hline
\end{tabular}


AGE AND GENDER DIFFERENCES IN DECISION MAKING PROFILES

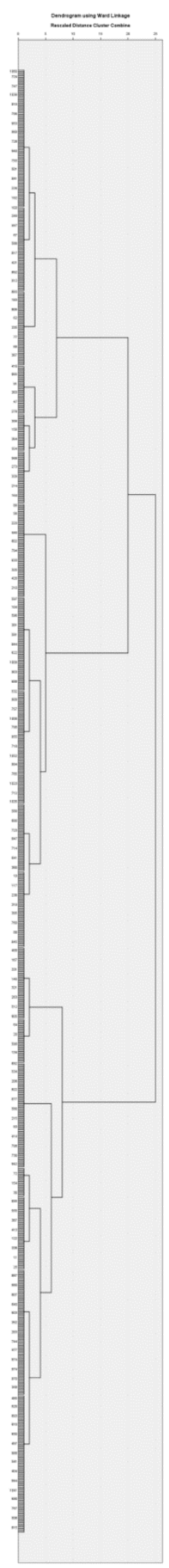

Figure 1. Dendogram depicting the three distinct decision-making style clusters. 
AGE AND GENDER DIFFERENCES IN DECISION MAKING PROFILES

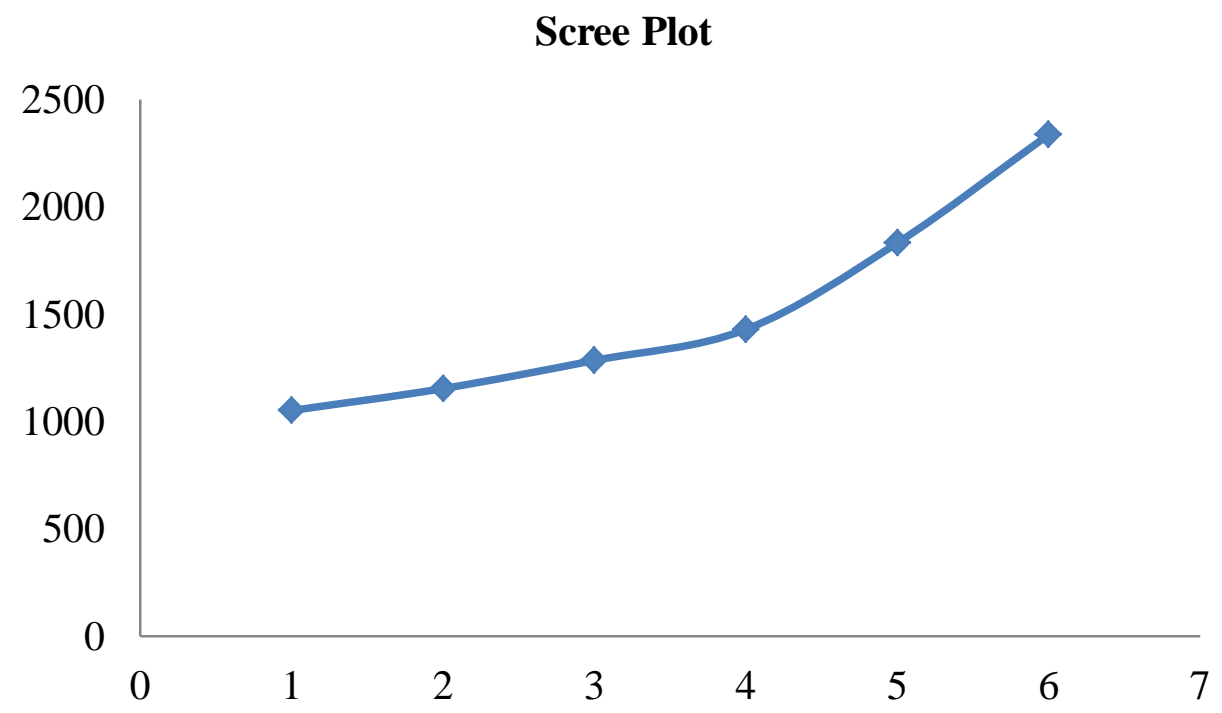

Figure 2. Cluster analysis scree plot supporting there being three decision-making style profiles. 
AGE AND GENDER DIFFERENCES IN DECISION MAKING PROFILES

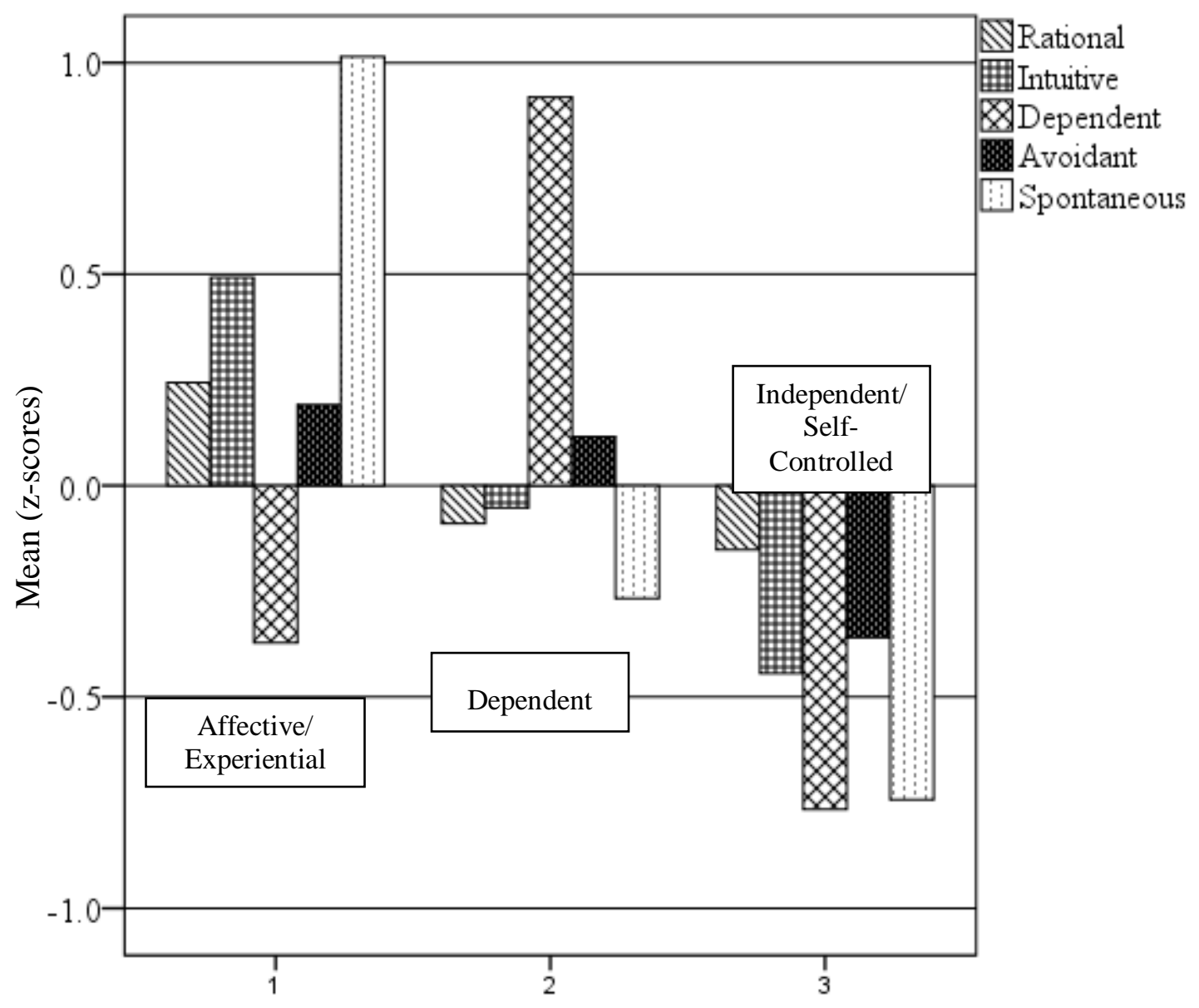

Clusters

Figure 3. Decision-making styles profile graph displaying the pattern of decision-making styles among the three groups (Affective/Experiential, Dependent, and Independent/Self-Controlled). 


\section{Appendix A}

\section{General Decision-Making Styles Inventory (Scott \& Bruce, 1995)}

\section{INSTRUCTIONS}

Listed below are statements describing how individuals go about making important decisions. Please indicate how much you agree with each statement by circling a number on the accompanying scale.

It ranges from 1 (completely disagree) to 5 (completely agree).

Rational

1. I double-check my information sources to be sure I have the right facts before making decisions.

2. I make decisions in a logical and systematic way.

3. My decision making requires careful thought.

4. When making a decision, I consider various options in terms of a specific goal. Intuitive

5. When making decisions, I rely upon my instincts.

6. When I make decisions, I tend to rely on my intuition.

7. I generally make decisions that feel right to me.

8. When I make a decision, it is more important for me to feel the decision is right than to have a rational reason for it.

9. When I make a decision, I trust my inner feelings and reactions. Dependent

10. I often need the assistance of other people when making important decisions.

11. I rarely make important decisions without consulting other people.

12. If I have the support of others, it is easier for me to make important decisions.

13. I use the advice of other people in making my important decisions.

14. I like to have someone to steer me in the right direction when I am faced with important decisions.

Avoidant

15. I avoid making important decisions until the pressure is on.

16. I postpone decision making whenever possible.

17. I often procrastinate when it comes to making important decisions.

18. I generally make important decisions at the last minute.

19. I put off making many decisions because thinking about them makes me uneasy. Spontaneous

20. I generally make snap decisions.

21. I often make decisions on the spur of the moment

22. I make quick decisions.

23. I often make impulsive decisions.

24. When making decisions, I do what seems natural at the moment. 


\section{Appendix B}

\section{Originally Proposed Analyses}

\section{Measures}

See Table 1 for descriptions of measures used in the originally proposed analyses.

\section{Research Question 1}

Are there age differences in the rational, intuitive, spontaneous, and dependent decisionmaking styles?

Hypothesis 1a. Based on findings from Finucane et al. (2002) where older adults preferred to delegate health-plan decisions more to others, older age will be associated with greater use of a dependent decision-making style.

Hypothesis 1b. Drawing from Horhota, Mienaltowski, and Blanchard-Fields (2012) findings that older adults have difficulty shifting between the rational/deliberative and experiential/affective systems used for decision making, older age will be associated with greater use of an intuitive decision-making style.

Hypothesis 1c. Older age will be associated with greater use of a spontaneous decisionmaking style (Horhota et al., 2012).

Hypothesis 1d. Based on Horhota et al. (2012), younger age will be associated with a greater use of a rational decision-making style.

Pearson’s $r$ correlations were conducted to address Research Question 1 regarding associations between age and decision-making styles (see Table 2). There was a significant association between age and the intuitive $(r(1066)=-.06, p=.047)$ and spontaneous $(r(1063)=-$ $.12, p<.01$ ) decision making styles, however the direction was opposite of what was predicted 
AGE AND GENDER DIFFERENCES IN DECISION MAKING PROFILES

for Hypotheses $1 \mathrm{~b}$ and 1c. Older age was hypothesized to be associated with participants being more likely to report a greater use of intuitive and spontaneous decision-making styles. The correlations found were also small in magnitude. In addition, there were no significant associations found between the rational and dependent decision-making styles with age. Thus Hypothesis 1a, which stated that older age would be associated with participants being more likely to report a greater use of a dependent decision-making style and Hypothesis 1d, which stated that younger age would be associated with participants being more likely to report a greater use of a rational decision-making style were not supported.

\section{Research Question 2}

Do individual difference characteristics (e.g. perceived ability, perceived health, and fluid cognitive ability) mediate age differences in dependent decision-making style (see Figure 1)?

Hypothesis 2a. Drawing from Finucane and Gullion (2010) who found that older adults with lower fluid intelligence also had lower comprehension abilities, as age increases, fluid cognitive ability will decrease and be associated with a dependent decision-making style.

Hypothesis 2b. Based on information from Strough and colleagues (2002) findings that when older adults had lower social comparison problem-solving abilities they had a greater preference for working with others, as age increases, perceived ability will decrease and be associated with a dependent decision-making style.

Hypothesis 2c. Previous research has found that good health status was a predictor of better decision-making competence (Finucane \& Gullion, 2010) and perceived health declines as people age (Finucane et al., 2002; Pinquart, 2001). Based on this information, as age increases, perceived health will decrease and be associated with a dependent decision-making style. 
AGE AND GENDER DIFFERENCES IN DECISION MAKING PROFILES

To address Research Question 2 regarding whether individual difference characteristics (e.g. perceived ability, perceived health, and fluid cognitive ability) mediated age differences in the dependent decision-making style, Hayes (2012) PROCESS macro was used to analyze the direct effect of age on the dependent decision-making style. Because the direct effect was not significant, indirect effects were examined to study the relation between age and the dependent decision-making style through individual characteristics (i.e. perceived decision making ability, perceived health, and fluid cognitive ability) (Hayes, 2012). As recommended by Hayes (2012), bias was calculated by using 95\% confidence intervals with 1,000 resamples for bootstrapping (see Table 2). There were no significant indirect effects of age through any of the individual characteristics on the dependent decision-making style. Hypotheses 2a through 2c which stated that as age increased, each individual characteristics would decrease and be associated with a greater likelihood of reporting a dependent decision-making style were not supported.

Exploratory analyses. Exploratory analyses were conducted using separate models to test direct and indirect effects of age on the four other decision-making styles. The direct effect was not significant for the rational, intuitive, or spontaneous decision-making styles. Indirect effects were then examined in each of the three models to study the relation between age and these three decision-making styles through individual characteristics (i.e. perceived decisionmaking ability, perceived health, and fluid cognitive ability). Bias was calculated by using 95\% confidence intervals with 1,000 resamples for bootstrapping (see Tables 3-5). There were no significant indirect effects of age through any of the individual characteristics for the rational, intuitive, or spontaneous decision-making styles.

There were significant findings regarding the avoidant decision-making style (see Table 6). Greater age was associated with a lower likelihood that participants reported using an 
AGE AND GENDER DIFFERENCES IN DECISION MAKING PROFILES

avoidant decision-making style, $\mathrm{B}=-.0085, S E=.0025, p<.001$, and with a lower perceived decision-making ability in how their ability has changed with age (temporal), $b=-.0130, S E=$ $.0015, p<.001$. After controlling for age, higher perceived decision-making ability in comparison to their abilities with age, was associated with a lower likelihood that participants reported using an avoidant decision-making style, $\mathrm{B}=-.1689, \mathrm{SE}=.0652, p=.001$. After controlling for perceived temporal decision-making ability, the association between age and the avoidant decision-making style was reduced, but age was still a significant predictor, $\mathrm{B}=-.0057$, $S E=$ $.0024, p=.02$ (see Figure 2). A Sobel test was conducted and found partial mediation in the model, $z=1.95, p=.05$. These findings suggest that those who perceived themselves to have higher decision-making ability as they have aged were more likely to feel comfortable with approaching, rather than postponing, decisions.

\section{Research Question 3}

Do individual's perceived abilities moderate the relationship between age and rational, intuitive, spontaneous, and dependent decision-making styles (see Figure 3)?

Hypothesis 3a. Drawing from Strough and colleagues (2002), older adults with high perceived ability will be more likely to have a rational decision-making style than older adults with low perceived ability.

To address Research Question 3 regarding perceived changes in ability with decision making over time (temporal comparisons) and perceived ability in relation to other people (social comparisons) as moderating the relationship between age and the decision-making styles, two multiple regressions were conducted using SPSS. Temporal and social comparison perceived decision-making ability were moderately correlated $(r=.48, p<.001)$, suggesting an association between the two, however, analyzing them separately was important in order to measure two 
AGE AND GENDER DIFFERENCES IN DECISION MAKING PROFILES

separate facets of decision-making ability. Relationships between variables of interest and perceived decision-making ability differed depending on the specific type. For these reasons, separate multiple regressions were completed for temporal and social decision-making abilities.

For hypothesis 3a, a multiple regression was conducted with the rational decision-making style as the outcome variable. In Step 1 of the regression, the centered variables for age and temporal decision-making ability were entered. In Step 2, the interaction of age and temporal decision-making ability was added to the model. In the final model (see Table 7), temporal decision-making ability and the age $\mathrm{X}$ temporal decision-making ability interaction was entered and was found to significantly relate to the rational decision-making style. The simple slopes were graphed and further indicated that those who were younger than 40 years old, with greater temporal decision-making ability, were more likely to report using a rational decision-making style $\mathrm{B}=.003, \mathrm{SE}=.003, p=.003$ (see Figure 4 ).

The same steps were conducted for the second multiple regression, but used social decision-making ability in place of temporal. In the final model (see Table 8), there was no significant change once the interaction term was added. In Step 1, however, higher social decision-making ability was significantly associated with reporting a greater use of the rational decision making style, $\mathrm{B}=.238, \mathrm{SE}=.042, p<.001$. Hypothesis 3a, stating that older adults with higher perceived decision-making ability would be more likely to report using a rational decision-making style was not supported. Results suggest that temporal decision-making ability accounted for the relationship with the rational decision-making style more for adults younger than 40 years old, rather than those greater than 53 years old. 
AGE AND GENDER DIFFERENCES IN DECISION MAKING PROFILES

Hypothesis $3 \mathbf{b}$. Older adults with high perceived ability will be less likely to have an intuitive decision-making style than older adults with low perceived ability (Horhota et al., 2012; Strough et al., 2002).

For hypothesis 3b, a multiple regression was conducted with the intuitive decisionmaking style as the outcome variable. In the Step 1 of the regression, the centered variables for age and temporal decision-making ability were entered. In Step 2, the interaction of age and temporal decision-making ability was added to the model. In the final model (see Table 9), there was no significant change with the interaction term added to the model.

The same steps were conducted for the second multiple regression, but used social decision-making ability in place of temporal. In the final model (see Table 10), there was no significant change once the interaction term was added. In Step 1, older age was significantly associated with being less likely to report using an intuitive decision-making style, $\mathrm{B}=-.003$, SE $=.002, p=.037$.

Hypothesis 3c. Older adults with high perceived ability will be less likely to have a spontaneous decision-making style than older adults with low perceived ability (Horhota et al., 2012; Strough et al., 2002).

For hypothesis 3c, a multiple regression was conducted with the spontaneous decisionmaking style as the outcome variable. In Step 1 of the regression, the centered variables for age and temporal decision-making ability were entered. In the Step 2, the interaction of age and temporal decision-making ability was added to the model. In the final model (see Table 11), there was no significant change with the interaction term added to the model. However, in Step 1 age did significantly contribute to the variance accounted for, $\mathrm{B}=-.136, \mathrm{SE}=.002, p=<.001$. 
AGE AND GENDER DIFFERENCES IN DECISION MAKING PROFILES

Thus, older age was associated with being less likely to report using a spontaneous decisionmaking style.

The same steps were conducted for the second multiple regression, but used social decision-making ability in place of temporal. In the final model (see Table 12), there was no significant change once the interaction term was added. In Step 1, older age was significantly associated with being less likely to report using a spontaneous decision-making style, $\mathrm{B}=-.121$, $\mathrm{SE}=.002, p=<.001$.

Hypothesis 3d. Older adults with high perceived ability will be less likely to have a dependent decision-making style than older adults with low perceived ability (Finucane et al., 2002; Strough et al., 2002).

For hypothesis 3d, a multiple regression was conducted with the dependent decisionmaking style as the outcome variable. In Step 1 of the regression, the centered variables for age and temporal decision-making ability were entered. In Step 2, the interaction of age and temporal decision-making ability was added to the model. In the final model (see Table 13), there was no significant change with the interaction term added to the model.

The same steps were conducted for the second multiple regression, but used social decision-making ability in place of temporal. In the final model (see Table 14), there was no significant change once the interaction was added. In Step 1, higher social decision-making ability was significantly associated with being less likely to report using a spontaneous decisionmaking style, $\mathrm{B}=-.123, \mathrm{SE}=.002, p=<.001$.

Exploratory analyses were conducted using the avoidant decision-making style as the outcome variable in multiple regressions. In Step 1 of the regression, the centered variables for age and temporal decision-making ability were entered. In Step 2, the interaction of age and 
AGE AND GENDER DIFFERENCES IN DECISION MAKING PROFILES

temporal decision-making ability was added to the model. In the final model (see Table 15), there was no significant change once the interaction term was added. In Step 1, those who were older in age $(\mathrm{B}=.169, \mathrm{SE}=.002, p<.001)$ and those who had higher temporal decision-making ability ( $\mathrm{B}=.229$, SE $=.051, p<.001)$ were less likely to report using an avoidant decisionmaking style.

The same steps were conducted for the second multiple regression, but used social decision-making ability in place of temporal. In the final model (see Table 16), there was no significant change once the interaction term was added. In Step 1, however, those who were older in age $(\mathrm{B}=.166, \mathrm{SE}=.002, p<.001)$ and those who had higher temporal decision-making ability $(\mathrm{B}=.249$, SE $=.052, p<.001)$ were less likely to report using an avoidant decisionmaking style.

For most of the decision-making styles, except for rational, the relationship between age and decision-making styles did not seem to change as a function of a person's perceptions of their own decision-making abilities in comparison to same-aged peers and across time.

\section{Research Question 4}

Are there gender differences in rational, intuitive, and dependent decision-making styles?

Hypothesis 4a. Based on Sinclair and colleagues (2010) findings, men will be more likely than women to report using a rational decision-making style.

Hypothesis $\mathbf{4 b}$. Women will be more likely than men to report using an intuitive decision-making style (Sinclair et al., 2010).

Hypothesis 4c. Drawing from Philips and colleagues (1984), women will be more likely than men to report using a dependent decision-making style. 
AGE AND GENDER DIFFERENCES IN DECISION MAKING PROFILES

To address Research Question 4, a Multivariate Analysis of Variance (MANOVA) was conducted to assess gender differences within the rational, intuitive, and dependent decisionmaking styles (see Table 17). Hypotheses 4b and 4c were confirmed, in that women were more likely to report using intuitive and dependent decision-making styles than men were. The dependent decision-making scores did not pass Levene’s test for homogeneity of variance, therefore results are reported based on not assuming equal variances. These findings suggest that women are more likely to rely on feelings and utilize other’s advice when making general decisions. However, caution must be yielded when interpreting the data as the magnitude of the effect sizes was relatively small.

Multiple regressions were also conducted to assess whether age moderated the relationship between gender and decision-making styles.

Rational decision-making style. For the first regression, the rational decision-making style was the outcome variable. In Step 1 , the centered variable for age $(p=.71)$ and gender $(p=$ .44) was entered where they were not found to be significant predictors, $(\mathrm{F}(2,1062)=.34, p=$ .71). In the Step 2, the interaction term for age and gender were added to the model. In the final model (see Table 18), there was no significant change once the interaction term was added.

Intuitive decision-making style. For the second regression, the intuitive decisionmaking style was the outcome variable. In Step 1, the centered variable for age $(p=.10)$ and gender $(p=.02)$ were entered and the model was significant at step one, $(\mathrm{F}(2,1063)=4.93, p=$ .01). Females were more likely to report using an intuitive decision-making style, $\mathrm{B}=.115$, SE $=.047, p=.02$. In Step 2, the interaction term for age and gender was added to the model. In the final model (see Table 19), there was no significant change once the interaction term was added. 
AGE AND GENDER DIFFERENCES IN DECISION MAKING PROFILES

Dependent decision-making style. For the third regression, the dependent decisionmaking style was the outcome variable. In Step 1 , the centered variable for age $(p=.48)$ and gender $(p=.03)$ were entered and approached significance, $(\mathrm{F}(2,1063)=2.86, p=.06)$. Gender was a significant predictor in that females were more likely to report using an intuitive decisionmaking style, $\mathrm{B}=.123, \mathrm{SE}=.06, p=.03$. In Step 2, the interaction term for age and gender was added to the model. In the final model (see Table 20), there was no significant change once the interaction term was added.

\section{Exploratory Analyses}

Hierarchical regressions were conducted with each decision-making style (rational, intuitive, spontaneous, and dependent) as the dependent variable. Demographic variables (i.e. age in years, gender, ethnicity, family income, and education) were entered in Step 1; perceived decision making ability (temporal and social), fluid cognitive ability, and perceived health were entered in Step 2 (see Table 21).

For the rational decision-making style, the Step 1 model was not significant, $(F(5$, $721)=.736, p=.597$ ) and there were no significant predictors; at Step 2, the change in variance accounted for $\left(\Delta \mathrm{R}^{2}=.038\right)$, was significant $(\Delta \mathrm{F}(4,717)=7.17, p<.001)$, and greater perceived decision-making ability in comparison to same-age peers was significantly associated with being more likely to report using the rational decision-making style $(p<.001)$. There were no other significant predictors at Step 2.

In Step 1 for the intuitive decision-making style, the model was significant $(F(5,722)=$ 3.91, $p=.002$ ), and having more education related to being less likely to report using an intuitive decision-making style $(p=.005)$; but the change in variance $\left(\Delta \mathrm{R}^{2}=.007\right)$, was not significant in Step $2(F(4,718)=1.30, p=.267)$. 
AGE AND GENDER DIFFERENCES IN DECISION MAKING PROFILES

For the dependent decision-making style, the Step 1 model was not significant (F(5, $722)=.1 .16, p=.327$ ) and there were no significant predictors; at Step 2, the change in variance accounted for $\left(\Delta \mathrm{R}^{2}=.021\right)$, was significant $(\Delta \mathrm{F}(4,718)=3.91, p=.004)$, and lower perceived decision-making ability in comparison to same-age peers was associated with being more likely to report using the dependent decision-making style $(p<.001)$.There were no other significant predictors at Step 2.

In Step 1 for the spontaneous decision-making style, the model was significant $(F(5$, $721)=3.12, p=.007)$, where gender $(p=.003)$ and age $(p=.025)$ were significant predictors; but the change in variance $\left(\Delta \mathrm{R}^{2}=.005\right)$, was not significant in Step $2(\mathrm{~F}(4,717)=2.18, p=.022)$. At Step 2, men were more likely to report using a spontaneous decision-making style $(p=.003)$ and older adults were less likely to report using a spontaneous decision-making style $(p=.03)$.

In Step 1 for the avoidant decision-making style, the model was significant $(F(5,722)=$ 3.32, $p=.006)$, where age $(p=.006)$ and family income $(p=.004)$ were significant predictors. Older age and lower family income were associated with being less likely to report using an avoidant decision-making style.

At Step 2 the change in variance $\left(\Delta \mathrm{R}^{2}=.087\right)$, was significant $(\mathrm{F}(4,718)=9.76, p=$ $<.001)$. Age $(p<.001)$, gender $(p=.017)$, perceived health $(p=.004)$ and temporal comparison $(p=.015)$ along with social comparison $(p<.001)$ perceived decision-making abilities were a significant predictors. Older age, better perceived decision-making abilities (temporal and social), and better perceived health were associated with being less likely to report using an avoidant decision-making style. Males were also more likely to report using an avoidant decision-making style. 
AGE AND GENDER DIFFERENCES IN DECISION MAKING PROFILES

Table 1

Measures

Perceived Decision-Making Ability

1 (better), 2 (the same), 3 (not as good); 6 items

(adapted from Strough et al., 2002)

Temporal (3 items; $\alpha=.84$ ) “As I have gotten older, my ability to make decisions is..."

Social (3 items; $\alpha=.81$ ) "Compared with people your age, would you say your ability to make decisions is..."

Perceived Health

(Lawton et al., 1982) $(\alpha=.75)$

1 (better), 2 (the same), 3 (not as good); 4 items

"Is your health now better, about the same, or not as good as it was 3 years ago?"

Fluid Cognitive Ability-number series (Woodcock et al., 2001)
Block Adaptive Testing format: Determine pattern of numbers and missing value; 15 items

Mathematical reasoning test of fluid cognitive ability

"Please complete the series of numbers. 3, 5, 7, 
Table 2

Correlations

\begin{tabular}{|c|c|c|c|c|c|c|c|c|c|c|c|c|c|c|c|}
\hline Variable & & 1 & 2 & 3 & 4 & 5 & 6 & 7 & 8 & 9 & 10 & 11 & 12 & 13 & 14 \\
\hline \multirow[t]{2}{*}{ 1. Gender } & & 1 & $-.130 * *$ & $.063^{*}$ & $-.091^{* *}$ & $-.100 * *$ & -0.023 & $.081 * *$ & $.070 *$ & -0.021 & $-.099 * *$ & 0.027 & $-.113^{* *}$ & $-.121 * *$ & -0.004 \\
\hline & $N$ & & 1075 & 1072 & -1074 & 1075 & 1065 & 1066 & 1066 & 1066 & 1063 & 1054 & 1054 & 745 & 1056 \\
\hline \multirow[t]{2}{*}{ 2. Age } & & & 1 & $-.239 * *$ & $.090 * *$ & 0.037 & -0.008 & $-.061^{*}$ & -0.03 & $-.107^{* *}$ & $-.118 * *$ & $-.295^{* *}$ & -0.058 & -0.035 & -0.027 \\
\hline & $N$ & & & 1072 & 1074 & 1075 & 1065 & 1066 & 1066 & 1066 & 1063 & 1054 & 1054 & 745 & 1056 \\
\hline \multirow[t]{2}{*}{ 3. Ethnicity } & & & & 1 & $-.142^{* *}$ & $-.075^{*}$ & 0.055 & 0.002 & -0.051 & 0.04 & 0.018 & 0.055 & 0.038 & -0.054 & 0.005 \\
\hline & $N$ & & & & 1071 & 1072 & 1062 & 1063 & 1063 & 1063 & 1060 & 1051 & 1051 & 745 & 1053 \\
\hline \multirow[t]{2}{*}{ 4. Income } & & & & & 1 & $.377^{* *}$ & -0.011 & $-.082^{* *}$ & $.064 *$ & $-.099 * *$ & -0.048 & $.112 * *$ & $.101 * *$ & $.233^{* *}$ & $.228 * *$ \\
\hline & $N$ & & & & & 1074 & 1064 & 1065 & 1065 & 1065 & 1062 & 1053 & 1053 & 744 & 1055 \\
\hline \multirow[t]{2}{*}{ 5. Education } & & & & & & 1 & 0.012 & $-.130 * *$ & $.071^{*}$ & 0.004 & -0.041 & $.071^{*}$ & $.085 * *$ & $.322 * *$ & $.150 * *$ \\
\hline & $N$ & & & & & & 1065 & 1066 & 1066 & 1066 & 1063 & 1054 & 1054 & 745 & 1056 \\
\hline \multirow[t]{2}{*}{ 6. Rational Style } & & & & & & & 1 & $.157 * *$ & $.073^{*}$ & $-.279 * *$ & $-.293^{* *}$ & $.111^{* *}$ & $.174 * *$ & 0.03 & 0.03 \\
\hline & $N$ & & & & & & & 1065 & 1065 & 1065 & 1062 & 1047 & 1047 & 741 & 1055 \\
\hline \multirow[t]{2}{*}{ 7. Intuitive Style } & & & & & & & & 1 & 0.011 & -0.024 & $.281 * *$ & 0.05 & 0.041 & $-.089 *$ & 0.036 \\
\hline & $N$ & & & & & & & & 1066 & 1066 & 1063 & 1048 & 1048 & 742 & 1056 \\
\hline \multirow[t]{2}{*}{ 8. Dependent Style } & & & & & & & & & 1 & $.263^{* *}$ & -0.015 & -0.021 & $-.120 * *$ & 0.037 & -0.017 \\
\hline & $N$ & & & & & & & & & 1066 & 1063 & 1048 & 1048 & 742 & 1056 \\
\hline \multirow{2}{*}{ 9. Avoidant Style } & & & & & & & & & & 1 & $.313^{* *}$ & $-.179 * *$ & $-.242 * *$ & -0.001 & $-.154 * *$ \\
\hline & $N$ & & & & & & & & & & 1063 & 1048 & 1048 & 742 & 1056 \\
\hline \multirow[t]{2}{*}{ 10. Spontaneous Style } & & & & & & & & & & & 1 & -0.016 & -0.012 & -0.014 & $-.072 *$ \\
\hline & $N$ & & & & & & & & & & & 1045 & 1045 & 740 & 1055 \\
\hline \multirow[t]{2}{*}{ 11.Temporal DM ability } & & & & & & & & & & & & 1 & $.480 * *$ & $.148 * *$ & $.231 * *$ \\
\hline & $N$ & & & & & & & & & & & & 3425 & 2029 & 1041 \\
\hline \multirow[t]{2}{*}{ 12. Social DM ability } & & & & & & & & & & & & & 1 & $.092 * *$ & $.253^{* *}$ \\
\hline & $N$ & & & & & & & & & & & & & 2030 & 1041 \\
\hline \multirow[t]{2}{*}{ 13. Cognitive } & & & & & & & & & & & & & & 1 & $.109 * *$ \\
\hline & $N$ & & & & & & & & & & & & & & 739 \\
\hline \multirow[t]{2}{*}{ 14. Health } & & & & & & & & & & & & & & & 1 \\
\hline & $N$ & & & & & & & & & & & & & & 1056 \\
\hline
\end{tabular}

Note. ${ }^{*} p<.05 ;{ }^{* *} p<.01$; The avoidant decision-making style was not included in the original proposal. 
AGE AND GENDER DIFFERENCES IN DECISION MAKING PROFILES

Table 2

Indirect effects of individual characteristics on age and dependent decision-making style

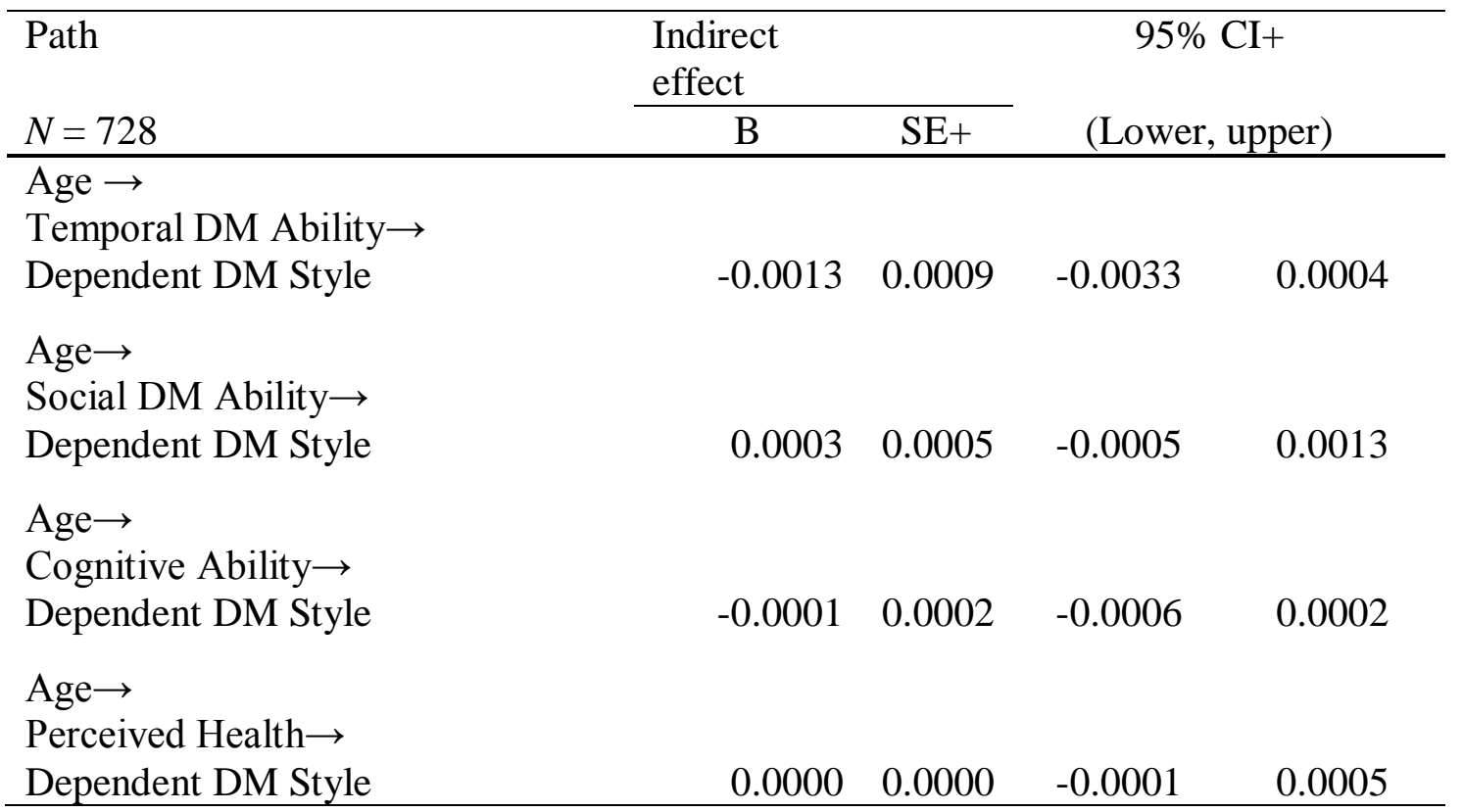


AGE AND GENDER DIFFERENCES IN DECISION MAKING PROFILES

Table 3

Indirect effects of individual characteristics on age and rational decision-making style

\begin{tabular}{|c|c|c|c|c|}
\hline Path & $\begin{array}{l}\text { Indirect } \\
\text { effect }\end{array}$ & & \multirow{2}{*}{\multicolumn{2}{|c|}{$\begin{array}{c}\text { 95\% CI+ } \\
\text { (Lower, upper) }\end{array}$}} \\
\hline$N=728$ & $\mathrm{~B}$ & $\mathrm{SE}+$ & & \\
\hline $\begin{array}{l}\text { Temporal DM Ability } \rightarrow \\
\text { Rational DM Style }\end{array}$ & -0.0001 & 0.0007 & -0.0016 & 0.0013 \\
\hline $\begin{array}{l}\text { Age } \rightarrow \\
\text { Social DM Ability } \rightarrow\end{array}$ & & & & \\
\hline Rational DM Style & -0.0004 & -0.0004 & -0.0012 & 0.0004 \\
\hline $\begin{array}{l}\text { Age } \rightarrow \\
\text { Cognitive Ability } \rightarrow \\
\text { Rational DM Style }\end{array}$ & 0.0000 & 0.0001 & -0.0005 & 0.0001 \\
\hline $\begin{array}{l}\text { Age } \rightarrow \\
\text { Perceived Health } \rightarrow \\
\text { Rational DM Style }\end{array}$ & 0.0000 & 0.0001 & -0.0001 & 0.0005 \\
\hline
\end{tabular}


AGE AND GENDER DIFFERENCES IN DECISION MAKING PROFILES

Table 4

Indirect effects of individual characteristics on age and intuitive decision-making style

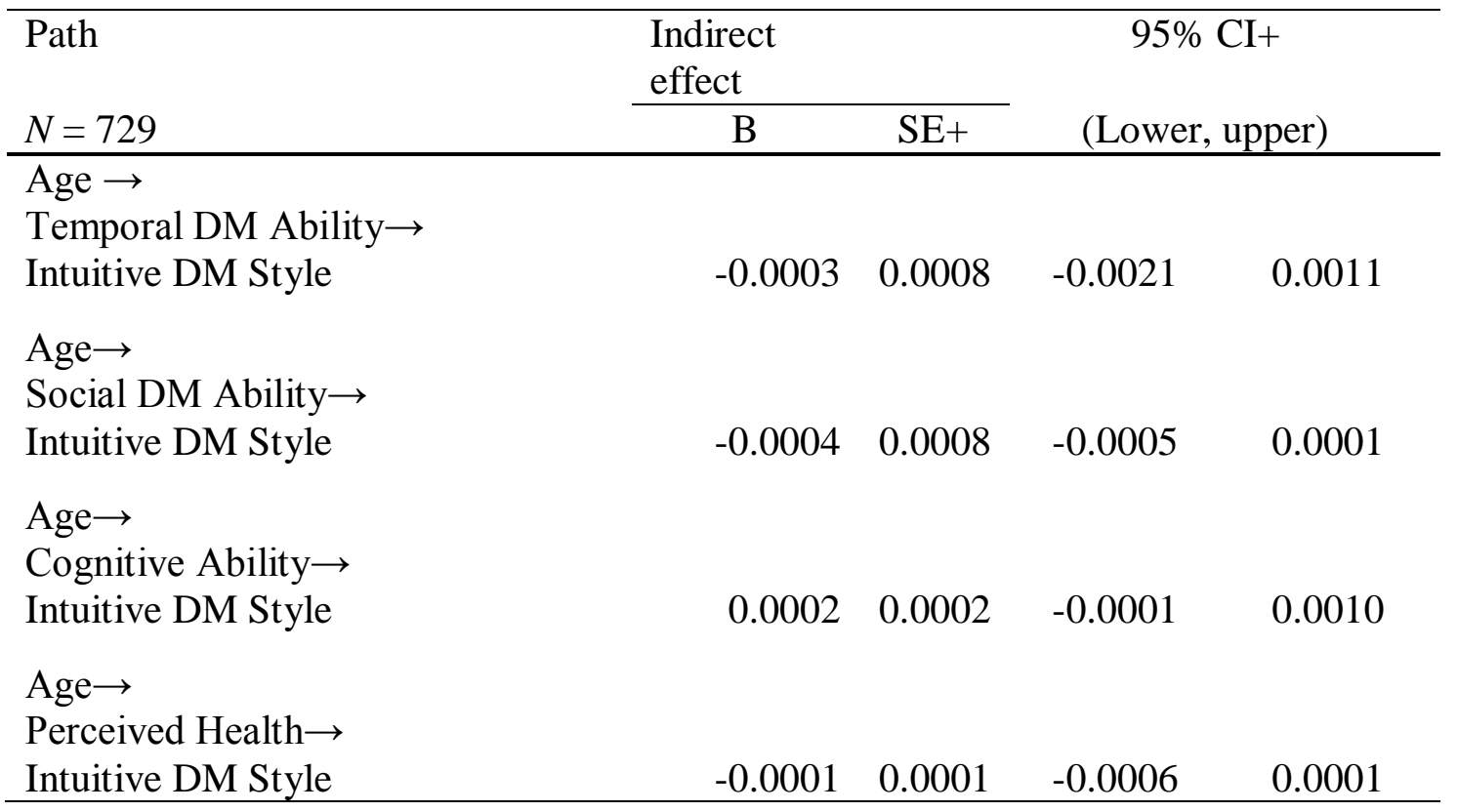


AGE AND GENDER DIFFERENCES IN DECISION MAKING PROFILES

Table 5

Indirect effects of individual characteristics on age and spontaneous decision-making style

\begin{tabular}{|c|c|c|c|c|}
\hline Path & $\begin{array}{l}\text { Indirect } \\
\text { effect }\end{array}$ & & \multirow{2}{*}{\multicolumn{2}{|c|}{$\begin{array}{c}\text { 95\% CI+ } \\
\text { (Lower, upper) } \\
\end{array}$}} \\
\hline$N=728$ & $\mathrm{~B}$ & $\mathrm{SE}+$ & & \\
\hline $\begin{array}{l}\text { Temporal DM Ability } \rightarrow \\
\text { Spontaneous DM Style }\end{array}$ & 0.0002 & 0.0009 & -0.0016 & 0.0019 \\
\hline $\begin{array}{l}\text { Age } \rightarrow \\
\text { Social DM Ability } \rightarrow\end{array}$ & & & & \\
\hline Spontaneous DM Style & 0.0000 & 0.0001 & -0.0001 & 0.0006 \\
\hline $\begin{array}{l}\text { Age } \rightarrow \\
\text { Cognitive Ability } \rightarrow \\
\text { Spontaneous DM Style }\end{array}$ & 0.0000 & 0.0001 & -0.0004 & 0.0002 \\
\hline $\begin{array}{l}\text { Age } \rightarrow \\
\text { Perceived Health } \rightarrow \\
\text { Spontaneous DM Style }\end{array}$ & 0.0001 & 0.0002 & -0.0001 & 0.0008 \\
\hline
\end{tabular}


AGE AND GENDER DIFFERENCES IN DECISION MAKING PROFILES

Table 6

Indirect effects of individual characteristics on age and avoidant decision-making style

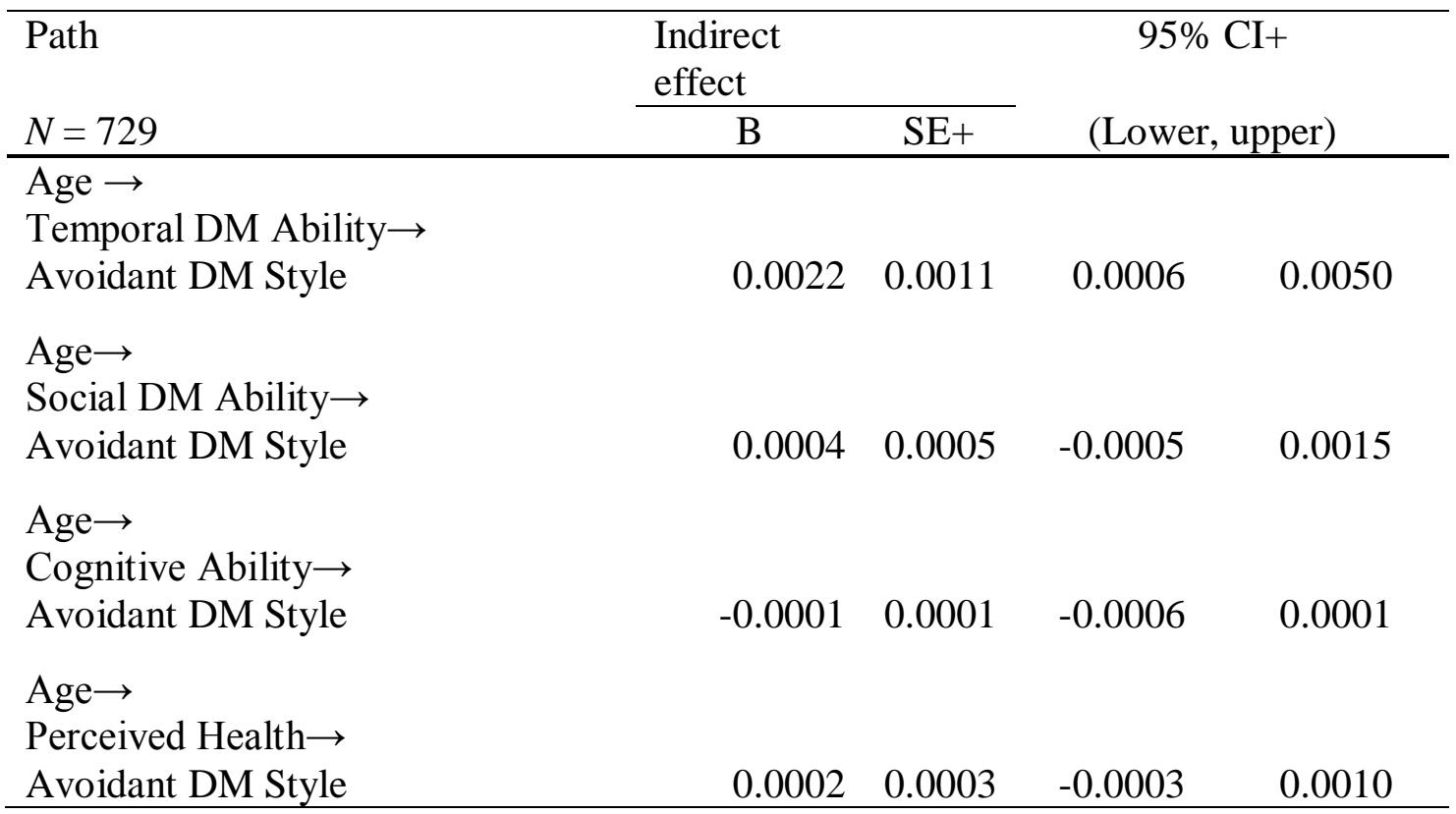


AGE AND GENDER DIFFERENCES IN DECISION MAKING PROFILES

Table 7

Moderation Analysis for Temporal Decision-Making Ability and Rational Decision-Making Style

\begin{tabular}{|c|c|c|c|c|c|c|}
\hline Variable & $\beta$ & $\mathrm{B}$ & $\mathrm{R}^{2}$ & $\Delta \mathrm{R}^{2}$ & $\mathrm{~F}$ & $\Delta \mathrm{F}$ \\
\hline Step 1 & & & 0.013 & 0.013 & 6.78 & $6.78^{* *}$ \\
\hline Age_centered & 0.03 & 0.001 & & & & \\
\hline Temporal DM Ability_centered & 0.12 & $0.15^{* * *}$ & & & & \\
\hline Step 2 & & & 0.018 & 0.008 & 7.55 & $9.00 * *$ \\
\hline Age_centered & 0.03 & 0.001 & & & & \\
\hline Temporal DM Ability_centered & 0.14 & $0.04 * * *$ & & & & \\
\hline Age X Temporal DM Ability & -0.1 & $0.003 * *$ & & & & \\
\hline
\end{tabular}

Note. $p<.05 * p<.01 * *, p<.001 * * * ; N=1046$. 
AGE AND GENDER DIFFERENCES IN DECISION MAKING PROFILES

Table 8

Moderation Analysis for Social Decision-Making Ability and Rational Decision-Making Style

\begin{tabular}{|c|c|c|c|c|c|c|}
\hline Variable & $\beta$ & $\mathrm{B}$ & $\mathrm{R}^{2}$ & $\Delta \mathrm{R}^{2}$ & $\mathrm{~F}$ & $\Delta \mathrm{F}$ \\
\hline Step 1 & & & 0.03 & 0.03 & 16.26 & $16.26 * * *$ \\
\hline Age_centered & 0.001 & $<.001$ & & & & \\
\hline Social DM Ability_centered & 0.174 & $0.238 * * *$ & & & & \\
\hline Step 2 & & & 0.03 & 0.00 & 10.87 & 0.13 \\
\hline Age_centered & 0.002 & 0.001 & & & & \\
\hline Social DM Ability_centered & 0.173 & $0.042 * * *$ & & & & \\
\hline Age X Social DM Ability & -0.011 & 0.003 & & & & \\
\hline
\end{tabular}

Note. $p<.05 * p<.01 * *, p<.001 * * * ; N=1047$. 
AGE AND GENDER DIFFERENCES IN DECISION MAKING PROFILES

Table 9

Moderation Analysis for Temporal Decision-Making Ability and Intuitive Decision-Making Style

\begin{tabular}{|c|c|c|c|c|c|c|}
\hline Variable & $\beta$ & $\mathrm{B}$ & $\mathrm{R}^{2}$ & $\Delta \mathrm{R}^{2}$ & $\mathrm{~F}$ & $\Delta \mathrm{F}$ \\
\hline Step 1 & & & 0.005 & 0.005 & 2.87 & 2.87 \\
\hline Age_centered & -0.06 & -0.003 & & & & \\
\hline Temporal DM Ability_centered & 0.03 & 0.048 & & & & \\
\hline Step 2 & & & 0.006 & 0.003 & 1.14 & 0.13 \\
\hline Age_centered & -0.06 & -0.003 & & & & \\
\hline Temporal DM Ability_centered & 0.03 & 0.044 & & & & \\
\hline Age X Temporal DM Ability & 0.01 & 0.001 & & & & \\
\hline
\end{tabular}

Note. $p<.05 * p<.01 * *, p<.001 * * * ; N=1048$. 
AGE AND GENDER DIFFERENCES IN DECISION MAKING PROFILES

Table 10

Moderation Analysis for Social Decision-Making Ability and Intuitive Decision-Making Style

\begin{tabular}{|c|c|c|c|c|c|c|}
\hline Variable & $\beta$ & $\mathrm{B}$ & $\mathrm{R}^{2}$ & $\Delta \mathrm{R}^{2}$ & $\mathrm{~F}$ & $\Delta \mathrm{F}$ \\
\hline Step 1 & & & 0.006 & 0.006 & 3.07 & $3.07 *$ \\
\hline Age_centered & -0.064 & $-0.003 *$ & & & & \\
\hline Social DM Ability_centered & 0.038 & 0.058 & & & & \\
\hline Step 2 & & & 0.008 & 0.002 & 2.92 & 2.6 \\
\hline Age_centered & -0.069 & $-0.004 *$ & & & & \\
\hline Social DM Ability_centered & 0.039 & 0.061 & & & & \\
\hline Age X Social DM Ability & 0.05 & 0.005 & & & & \\
\hline
\end{tabular}

Note. $p<.05 * p<.01 * *, p<.001 * * * ; N=1048$. 
AGE AND GENDER DIFFERENCES IN DECISION MAKING PROFILES

Table 11

Moderation Analysis for Temporal Decision-Making Ability and Spontaneous Decision-Making Style

\begin{tabular}{|c|c|c|c|c|c|c|}
\hline Variable & $\beta$ & $\mathrm{B}$ & $\mathrm{R}^{2}$ & $\Delta \mathrm{R}^{2}$ & $\mathrm{~F}$ & $\Delta \mathrm{F}$ \\
\hline Step 1 & & & 0.017 & 0.017 & 9.15 & $9.15^{* * *}$ \\
\hline Age_centered & -0.136 & -0.008 & & & & \\
\hline Temporal DM Ability_centered & -0.056 & -0.091 & & & & \\
\hline Step 2 & & & 0.017 & $<.001$ & 6.10 & 0.038 \\
\hline Age_centered & -0.136 & -0.008 & & & & \\
\hline Temporal DM Ability_centered & -0.054 & -0.089 & & & & \\
\hline Age X Temporal DM Ability & -0.006 & -0.001 & & & & \\
\hline
\end{tabular}

Note. $p<.05 * p<.01 * *, p<.001 * * * ; N=1045$. 
AGE AND GENDER DIFFERENCES IN DECISION MAKING PROFILES

Table 12

Moderation Analysis for Social Decision-Making Ability and Spontaneous Decision-Making

Style

\begin{tabular}{|c|c|c|c|c|c|c|}
\hline Variable & $\beta$ & $\mathrm{B}$ & $\mathrm{R}^{2}$ & $\Delta \mathrm{R}^{2}$ & $\mathrm{~F}$ & $\Delta \mathrm{F}$ \\
\hline Step 1 & & & 0.015 & 0.015 & 7.79 & $7.79 * * *$ \\
\hline Age_centered & -0.121 & $-0.007 * * *$ & & & & \\
\hline Social DM Ability_centered & -0.018 & -0.032 & & & & \\
\hline Step 2 & & & 0.016 & 0.001 & 5.54 & 1.05 \\
\hline Age_centered & -0.123 & $-0.008 * * *$ & & & & \\
\hline Social DM Ability_centered & -0.017 & -0.03 & & & & \\
\hline Age X Social DM Ability & 0.032 & 0.004 & & & & \\
\hline
\end{tabular}

Note. $p<.05 * p<.01 * *, p<.001 * * * ; N=1045$. 
AGE AND GENDER DIFFERENCES IN DECISION MAKING PROFILES

Table 13

Moderation Analysis for Temporal Decision-Making Ability and Dependent Decision-Making Style

\begin{tabular}{|c|c|c|c|c|c|c|}
\hline Variable & $\beta$ & $\mathrm{B}$ & $\mathrm{R}^{2}$ & $\Delta \mathrm{R}^{2}$ & $\mathrm{~F}$ & $\Delta \mathrm{F}$ \\
\hline Step 1 & & & 0.002 & 0.002 & 1.1 & 1.1 \\
\hline Age_centered & -0.043 & -0.003 & & & & \\
\hline Temporal DM Ability_centered & -0.034 & -0.058 & & & & \\
\hline Step 2 & & & 0.002 & $<.001$ & 0.76 & 0.09 \\
\hline Age_centered & -0.043 & -0.003 & & & & \\
\hline Temporal DM Ability_centered & -0.031 & -0.054 & & & & \\
\hline Age X Temporal DM Ability & -0.009 & -0.001 & & & & \\
\hline
\end{tabular}

Note. $p<.05^{*} p<.01 * *, p<.001 * * * ; N=1048$. 
AGE AND GENDER DIFFERENCES IN DECISION MAKING PROFILES

Table 14

Moderation Analysis for Social Decision-Making Ability and Dependent Decision-Making Style

\begin{tabular}{|c|c|c|c|c|c|c|}
\hline Variable & $\beta$ & $\mathrm{B}$ & $\mathrm{R}^{2}$ & $\Delta \mathrm{R}^{2}$ & $\mathrm{~F}$ & $\Delta \mathrm{F}$ \\
\hline Step 1 & & & 0.016 & 0.016 & 8.52 & $8.52 * * *$ \\
\hline Age_centered & -0.04 & -0.003 & & & & \\
\hline Social DM Ability_centered & -0.123 & $-0.225^{* * *}$ & & & & \\
\hline Step 2 & & & 0.016 & $<.001$ & 5.79 & 0.33 \\
\hline Age_centered & -0.038 & -0.006 & & & & \\
\hline Social DM Ability_centered & -0.123 & $-0.337 * * *$ & & & & \\
\hline Age X Social DM Ability & -0.018 & -0.01 & & & & \\
\hline
\end{tabular}

Note. $p<.05 * p<.01 * *, p<.001 * * * ; N=1048$. 
AGE AND GENDER DIFFERENCES IN DECISION MAKING PROFILES

Table 15

Moderation Analysis for Temporal Decision-Making Ability and Avoidant Decision-Making

Style

\begin{tabular}{rrrrrrr} 
& $\beta$ & $\mathrm{B}$ & $\mathrm{R}^{2}$ & $\Delta \mathrm{R}^{2}$ & $\mathrm{~F}$ & $\Delta \mathrm{F}$ \\
\hline \hline & & & 0.058 & 0.058 & 32.25 & $32.35^{* * *}$ \\
Step 1 Age_centered & -0.169 & $-0.01^{* * *}$ & & & & \\
Aemporal DM Ability_centered & -0.229 & $-0.374^{* * *}$ & & & & \\
Step 2 & & & 0.059 & $<.001$ & 21.62 & 0.407 \\
Age_centered & -0.169 & $-0.01^{* * *}$ & & & & \\
Temporal DM Ability_centered & -0.234 & $-0.382^{* * *}$ & & & & \\
Age X Temporal DM Ability & 0.02 & 0.002 & & & & \\
\hline
\end{tabular}

Note. $p<.05 * p<.01 * *, p<.001 * * * ; N=1048$. 
AGE AND GENDER DIFFERENCES IN DECISION MAKING PROFILES

Table 16

Moderation Analysis for Social Decision-Making Ability and Avoidant Decision-Making Style

\begin{tabular}{|c|c|c|c|c|c|c|}
\hline Variable & $\beta$ & $\mathrm{B}$ & $\mathrm{R}^{2}$ & $\Delta \mathrm{R}^{2}$ & $\mathrm{~F}$ & $\Delta \mathrm{F}$ \\
\hline Step 1 & & & 0.072 & 0.072 & 40.61 & $40.61 * * *$ \\
\hline Age_centered & -0.116 & $-0.007 * * *$ & & & & \\
\hline Social DM Ability_centered & -0.249 & $-0.436 * * *$ & & & & \\
\hline Step 2 & & & 0.073 & $<.001$ & 27.22 & 0.491 \\
\hline Age_centered & -0.118 & $-0.007 * * *$ & & & & \\
\hline Social DM Ability_centered & -0.248 & $-0.435 * * *$ & & & & \\
\hline Age X Social DM Ability & 0.021 & 0.003 & & & & \\
\hline
\end{tabular}

Note. $p<.05 * p<.01 * *, p<.001 * * * ; N=1048$. 
AGE AND GENDER DIFFERENCES IN DECISION MAKING PROFILES

Table 17

MANOVA for Gender and Decision-Making Styles

\begin{tabular}{|c|c|c|c|c|c|}
\hline \multirow[b]{2}{*}{ Measure and Group } & \multirow[b]{2}{*}{$\mathrm{N}$} & \multicolumn{2}{|c|}{ Score } & \multirow[b]{2}{*}{$\mathrm{F}$} & \multirow[b]{2}{*}{$\eta^{2}$} \\
\hline & & Mean & $S D$ & & \\
\hline Rational DM Style & & & & 0.59 & 0.001 \\
\hline Males & 468 & 4.19 & 0.64 & & \\
\hline Females & 597 & 4.15 & 0.71 & & \\
\hline Intuitive DM Style & & & & $6.65 * *$ & 0.006 \\
\hline Males & 469 & 3.58 & 0.77 & & \\
\hline Females & 597 & 3.71 & 0.75 & & \\
\hline Dependent DM Style & & & & $4.70 *$ & 0.004 \\
\hline Males & 469 & 3.03 & 0.85 & & \\
\hline Females & 597 & 3.16 & 0.89 & & \\
\hline
\end{tabular}

Note. $p<.05 * p=.01 * *$ 
AGE AND GENDER DIFFERENCES IN DECISION MAKING PROFILES

Table 18

Moderation Analysis for Rational DM Style

\begin{tabular}{|c|c|c|c|c|c|c|c|}
\hline \multirow{2}{*}{$\begin{array}{l}\text { Variable } \\
\text { Step } 1\end{array}$} & & $\beta$ & $\mathrm{B}$ & $\mathrm{R}^{2}$ & $\Delta \mathrm{R}^{2}$ & $\mathrm{~F}$ & $\Delta \mathrm{F}$ \\
\hline & & & & 0.001 & 0.001 & 0.34 & 0.713 \\
\hline & Age_centered & -0.011 & -0.001 & & & & \\
\hline & Gender & -0.024 & -0.033 & & & & \\
\hline \multirow[t]{4}{*}{ Step 2} & & & & 0.001 & 0 & 0.37 & 0.435 \\
\hline & Age_centered & -0.078 & -0.004 & & & & \\
\hline & Gender & -0.025 & -0.034 & & & & \\
\hline & Age X Gender & 0.07 & 0.002 & & & & \\
\hline
\end{tabular}


AGE AND GENDER DIFFERENCES IN DECISION MAKING PROFILES

Table 19

Moderation Analysis for Intuitive DM Style

\begin{tabular}{|c|c|c|c|c|c|c|c|}
\hline Variable & & $\beta$ & $\mathrm{B}$ & $\mathrm{R}^{2}$ & $\Delta \mathrm{R}^{2}$ & $\mathrm{~F}$ & $\Delta \mathrm{F}$ \\
\hline \multirow[t]{3}{*}{ Step 1} & & & & 0.009 & 0.009 & 4.93 & $4.93 * *$ \\
\hline & Age_centered & -0.051 & -0.003 & & & & \\
\hline & Gender & 0.075 & $0.115^{*}$ & & & & \\
\hline \multirow[t]{4}{*}{ Step 2} & & & & 0.011 & 0.002 & 4.10 & 0.12 \\
\hline & Age_centered & -0.209 & $-0.011 *$ & & & & \\
\hline & Gender & 0.072 & $0.111 *$ & & & & \\
\hline & Age X Gender & 0.164 & 0.005 & & & & \\
\hline
\end{tabular}

Note. $p<.05 * p<.01 * *, p<.001 * * * ; N=1066$ 
AGE AND GENDER DIFFERENCES IN DECISION MAKING PROFILES

Table 20

Moderation Analysis for Dependent DM Style

\begin{tabular}{|c|c|c|c|c|c|c|c|}
\hline Variable & & $\beta$ & $\mathrm{B}$ & $\mathrm{R}^{2}$ & $\Delta \mathrm{R}^{2}$ & $\mathrm{~F}$ & $\Delta \mathrm{F}$ \\
\hline \multirow[t]{3}{*}{ Step 1} & & & & 0.005 & 0.005 & 2.86 & 2.86 \\
\hline & Age_centered & -0.022 & -0.001 & & & & \\
\hline & Gender & 0.067 & $0.123^{*}$ & & & & \\
\hline \multirow[t]{4}{*}{ Step 2} & & & & 0.006 & 0.001 & 2.26 & 0.491 \\
\hline & Age_centered & 0.083 & 0.005 & & & & \\
\hline & Gender & 0.069 & $0.125 *$ & & & & \\
\hline & Age X Gender & -0.11 & -0.004 & & & & \\
\hline
\end{tabular}

Note. $p<.05 * p<.01 * *, p<.001 * * * ; N=1066$ 
AGE AND GENDER DIFFERENCES IN DECISION MAKING PROFILES

Table 21

Exploratory Hierarchical Regressions

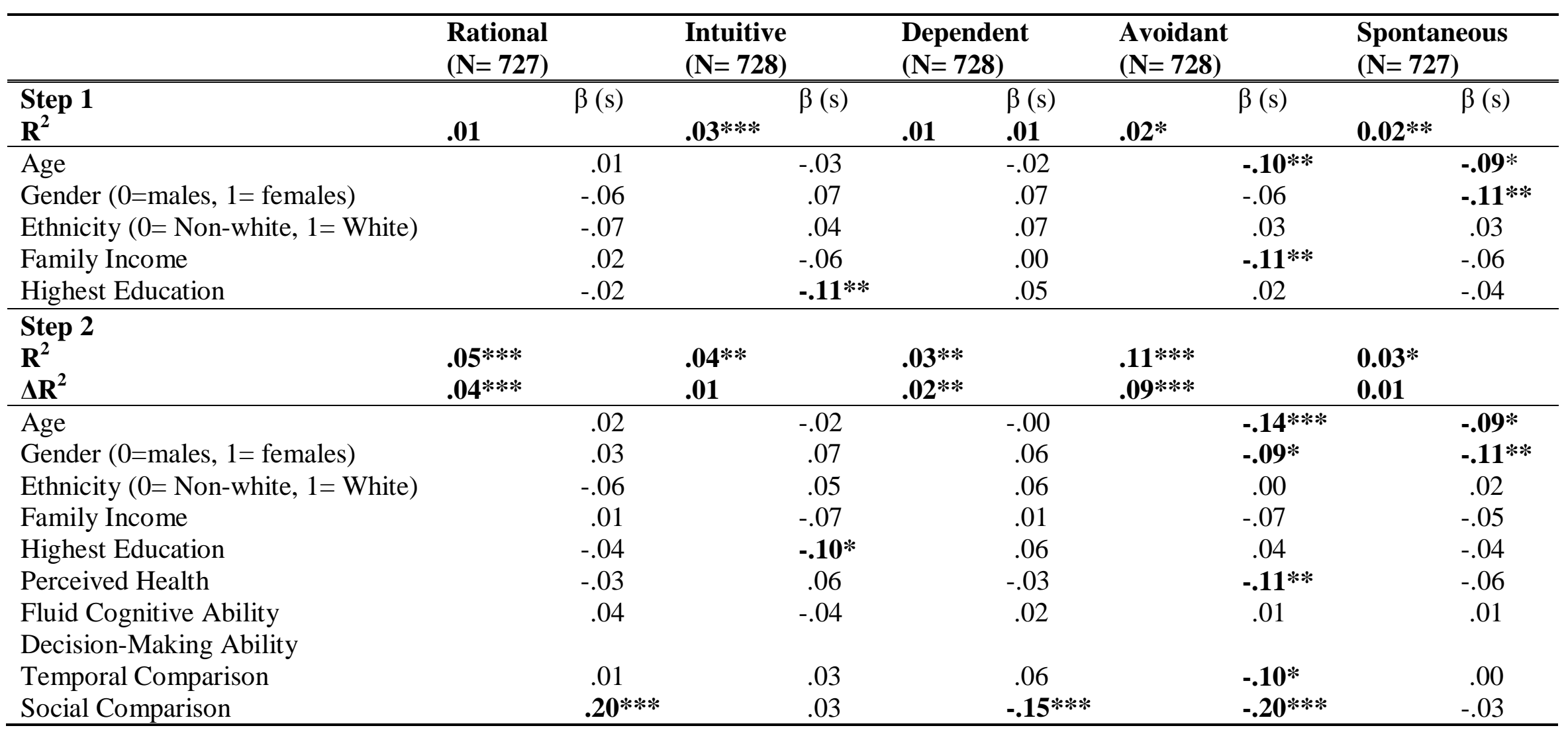




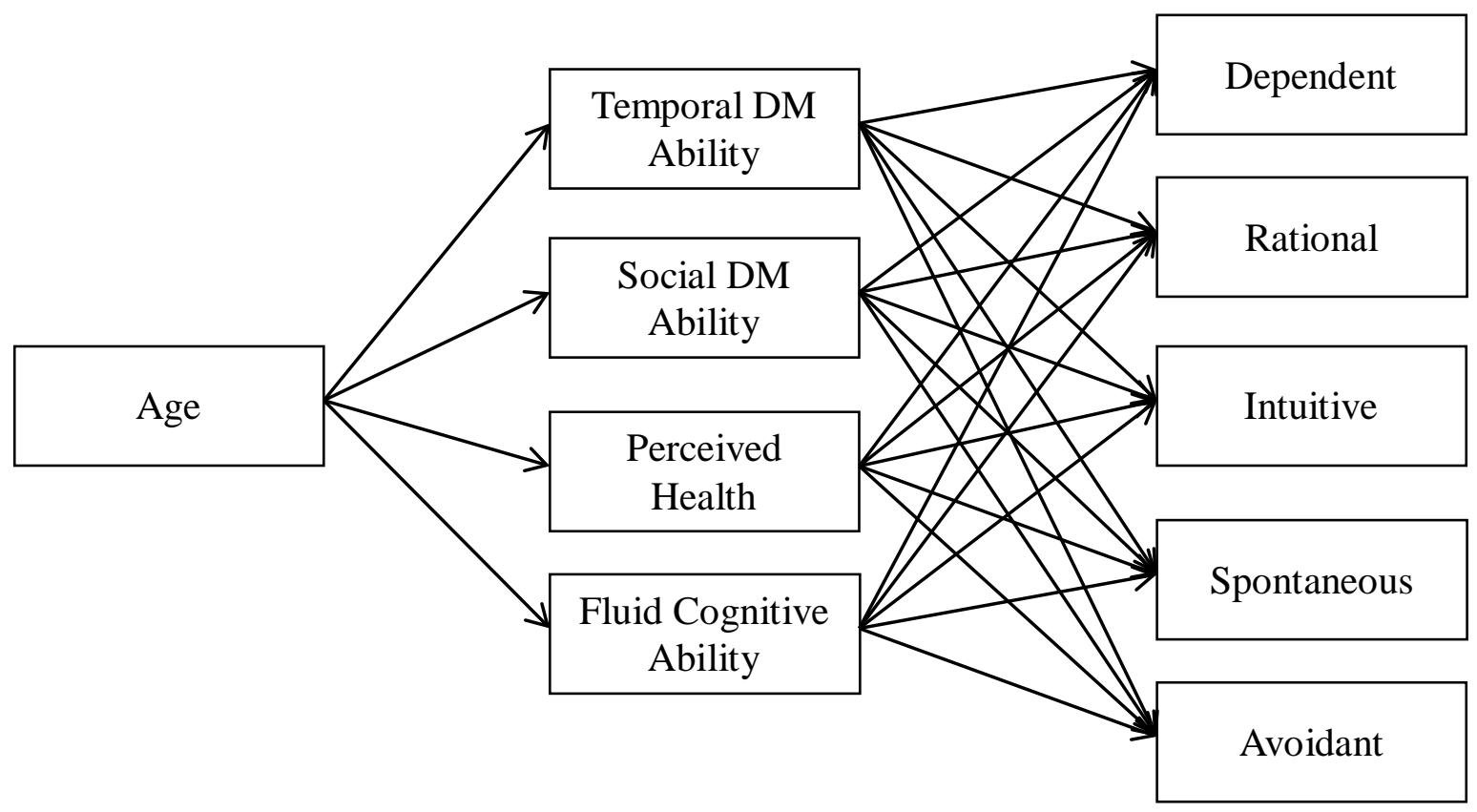

Figure 1. Conceptual model of mediation between age, individual difference characteristics, and decision-making styles. 


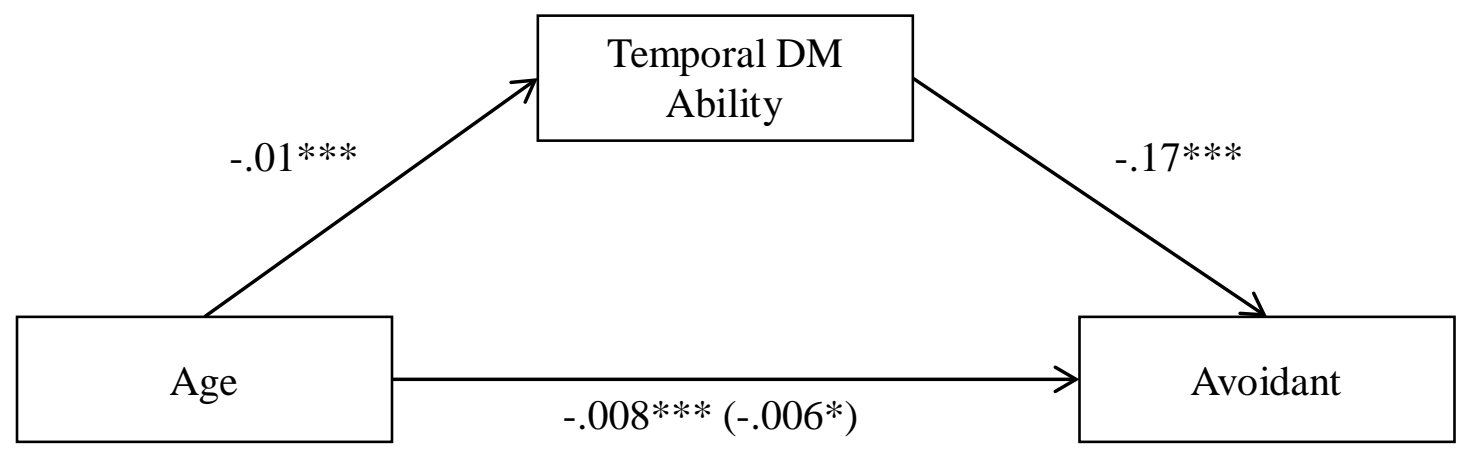

Figure 2. Mediation model with temporal decision-making ability accounting for partial mediation between age and the avoidant decision-making style. 


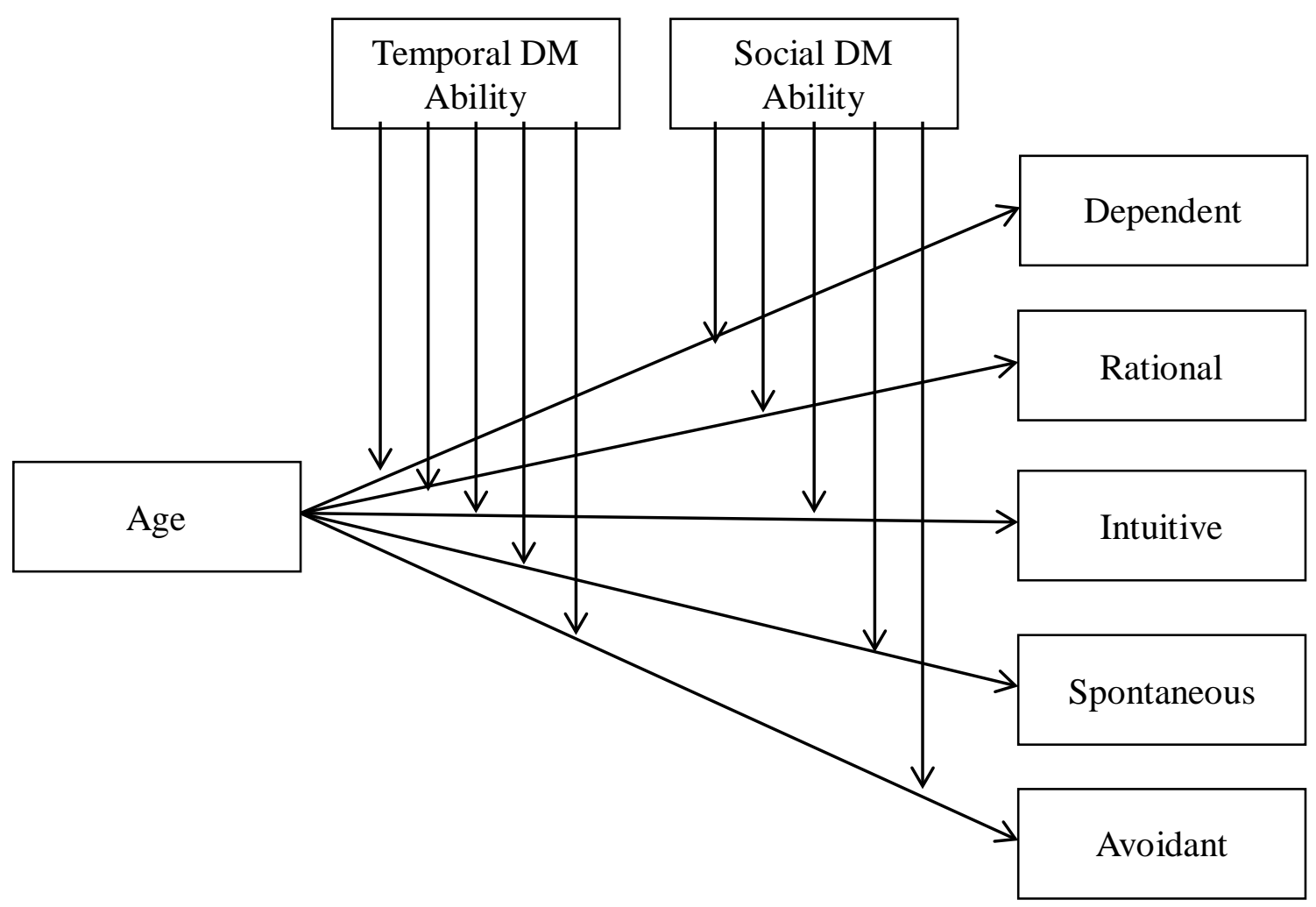

Figure 3.Conceptual model for associations between age by perceived decision-making ability interactions and the decision-making styles. 
AGE AND GENDER DIFFERENCES IN DECISION MAKING PROFILES

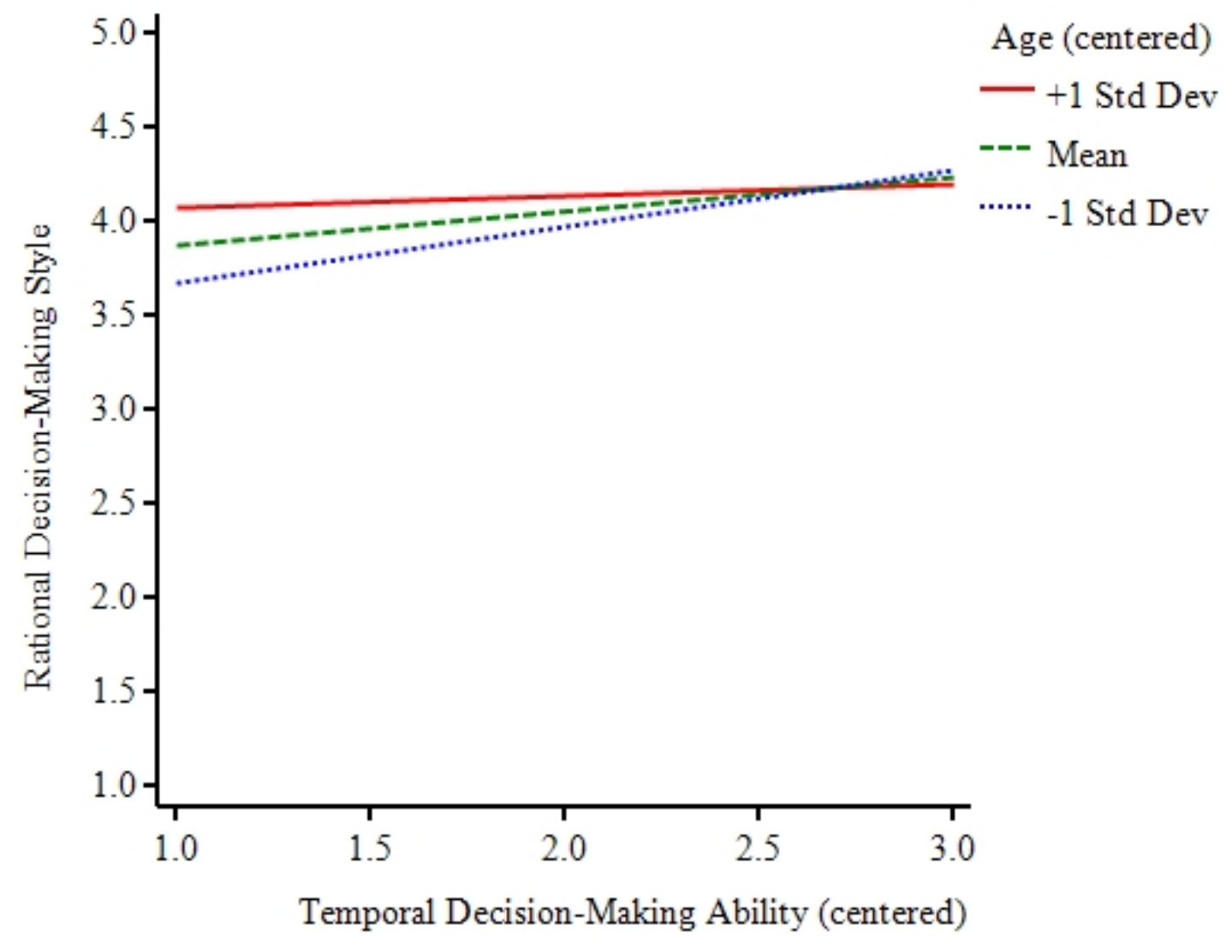

Figure 4. Associations between temporal decision-making ability and the rational decisionmaking style by age interaction graph. 
AGE AND GENDER DIFFERENCES IN DECISION MAKING PROFILES

\section{References}

Finucane, M. L., \& Gullion, C. M. (2010). Developing a tool for measuring the decision-making competence of older adults. Psychology and Aging, 25(2), 271-288. doi:10.1037/a0019106

Finucane, M. L., Slovic, P., Hibbard, J. H., Peters, E., Mertz, C. K., \& MacGregor, D. G. (2002). Aging and decision-making competence: An analysis of comprehension and consistency skills in older versus younger adults considering health-plan options. Journal of Behavioral Decision Making, 15(2), 141-164. doi:10.1002/bdm.407

Hayes, A. F. (2012). PROCESS: A versatile computational tool for observed variable mediation, moderation, and conditional process modeling [White paper]. Retrieved from http://www.afhayes.com/public/process2012.pdf

Horhota, M., Mienaltowski, A., Blanchard-Fields, F. (2012). If only I had taken my usual route...: Age-related differences in counter-factual thinking. Aging, Neuropsychology, and Cognition, 19(3), 339-361. doi: 10.1080/13825585.2011.615904

Pinquart, M. (2001). Correlates of subjective health in older adults: A meta-analysis. Psychology and Aging, 16(3), 414-426. doi:10.1037/0882-7974.16.3.414 
AGE AND GENDER DIFFERENCES IN DECISION MAKING PROFILES

\section{Originally Proposed Measures}

\section{Appendix C \\ Perceived Decision-Making Competence (Bruine de Bruin, Parker, \& Fischhoff, 2010)}

What percent of other people do you think are worse decision makers than you?

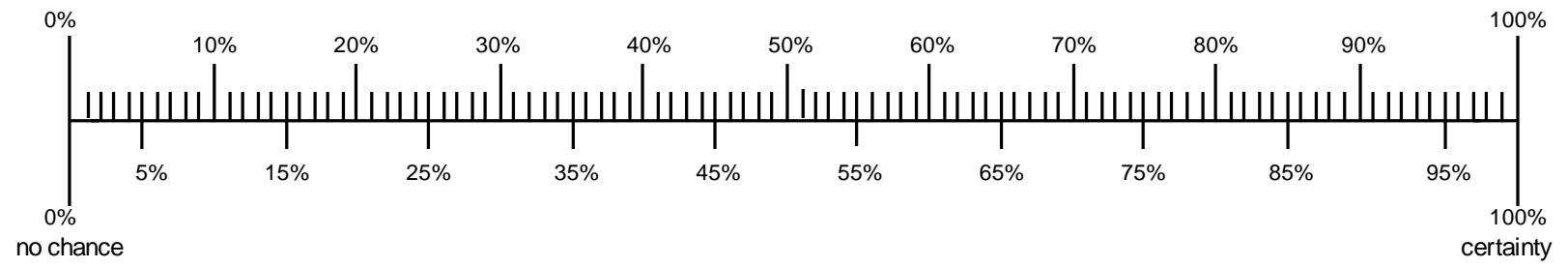

What percent of other people your age do you think are worse decision makers than you?

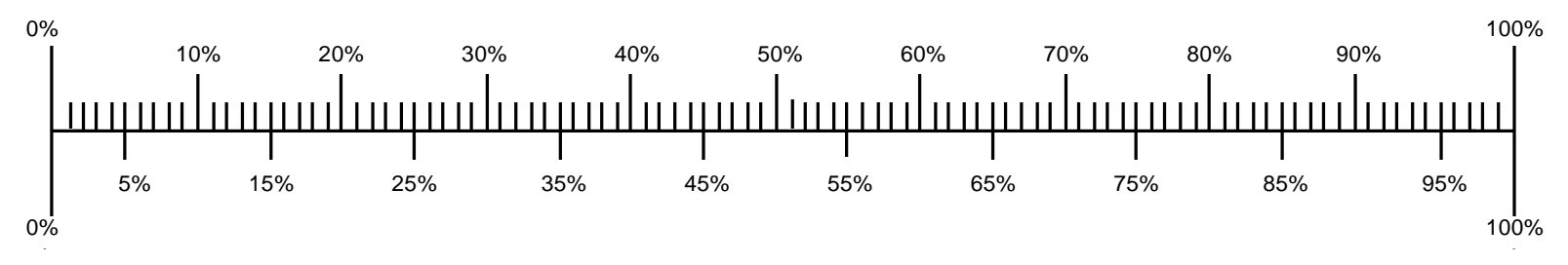

None 
AGE AND GENDER DIFFERENCES IN DECISION MAKING PROFILES

\section{Appendix D}

\section{Perceived Decision-Making Ability \\ (Adapted from Strough, Swenson \& Cheng, 2002)}

\section{Instructions}

As they age, some people notice changes in their ability to make decisions. Please answer the following items about how you view your ability to make decisions in light of your own aging.

\section{Temporal Comparison Subscale}

As I have gotten older, my ability to make decisions is:

Better

__ The Same

_ Not as good

As I have gotten older, my ability to make decisions about things that affect other people is:

\section{Better}

The Same

Not as good

As I have gotten older, my ability to make decisions about things that affect only me is:

Better

$\begin{array}{ll}\text { _ } & \text { The Same } \\ & \text { Not as good }\end{array}$

\section{Social Comparison Subscale}

Compared with most people your age, would you say your ability to make decisions is:

Better

_ The Same

_ Not as good

Compared with most people your age, would you say your ability to make decisions that affect only you is:

Better

The Same

N Not as good

Compared with most people your age, would you say your ability to make decisions that affect other people is:

Better

The Same

Not as good 
AGE AND GENDER DIFFERENCES IN DECISION MAKING PROFILES

\section{Appendix E}

\section{Perceived Health (Lawton et al., 1982)}

\section{INSTRUCTIONS}

Please circle the one that BEST describes you:

1.) How would you rate your overall health at the present time?

$$
\text { Excellent }
$$

$\begin{array}{ll}\square & \text { Good } \\ & \text { Fair } \\ & \text { Poor }\end{array}$

2.) Is your health now better, about the same, or not as good as it was 3 years ago?

Better
Same

3.) Do your health problems stand in the way of your doing the things you want to do? Not at all

_ A little

_ A great deal

4.) Compared with most other people your age, would you say your health is:

$$
\text { Better }
$$

